\title{
Optimum Design of Fully Composite, Unstiffened, Built-Up, Hybrid Steel Girder Using GRG, NLR, and ANN Techniques
}

\author{
Mohamed A. El-Aghoury, ${ }^{1}$ Ahmed M. Ebid $\mathbb{D}^{2},{ }^{2}$ and Kennedy C. Onyelowe $\mathbb{D}^{3}$ \\ ${ }^{1}$ Faculty of Engineering, Ain Shams University, Cairo, Egypt \\ ${ }^{2}$ Faculty of Engineering and Technology, Future University in Egypt, New Cairo, Egypt \\ ${ }^{3}$ Department of Civil and Mechanical Engineering, Kampala International University, Kampala, Uganda \\ Correspondence should be addressed to Kennedy C. Onyelowe; kennedychibuzor@kiu.ac.ug
}

Received 29 July 2021; Accepted 11 October 2021; Published 7 February 2022

Academic Editor: Claudio Mazzotti

Copyright (C) 2022 Mohamed A. El-Aghoury et al. This is an open access article distributed under the Creative Commons Attribution License, which permits unrestricted use, distribution, and reproduction in any medium, provided the original work is properly cited.

\begin{abstract}
Composite steel beams are commonly used element in multistorey steel buildings to enhance floor economy and serviceability and provide more clear height. Due to the low level of stress in the webs of such beams, hybrid sections are used where the flanges have higher strength than the webs. A lot of earlier research was carried out to optimize the design of the hybrid and nonhybrid composite steel beams under both static loading and dynamic behavior. However, there is still a need to develop a more practical optimization method. The aim of this research is to develop simple and practical equations to determine the optimum cross section dimensions for both shored and unshored, simply supported, hybrid and nonhybrid, composite steel beam under static loads. To achieve that goal, a research program of two phases was carried out. The first phase was generating a database of 504 composite beams with different steel grades for flanges and webs, subjected to different values of bending moment. The cross section of each beam in the database was optimized using GRG technique to minimize the cost considering the unit price of each steel grade. In the second phase, the generated database was divided into training and validation subsets and used to develop two predictive models using Nonlinear Regression (NLR) technique and Artificial Neural Network (ANN) technique to predict the optimum cross section dimensions and hence the optimum weight and cost. The accuracies of the developed models were measured in terms of average error percent. NLR and ANN models showed average error percent of $16 \%$ and $11 \%$, respectively.
\end{abstract}

\section{Introduction}

Connecting steel beams to concrete decks to form composite floors is commonly used in multistorey steel buildings. The use of this system reduces both weight and cost of floors and increases their stiffness and severability. From construction point of view, composite floor could be shored or unshored. Shored floor is supported during concrete casting and till concrete hardening; accordingly, composite section supports all loads. On the other hand, unshored floor is casted without supporting, and hence weights of steel and concrete are supported by steel section only while the rest of loads are supported by the composite section. Steel part of the composite could be beam (hot rolled section, built-up section, or castellated beam), truss, or another girder type such as Vierendeel.
To achieve fully composite action, shear connectors between steel section and concrete deck should be strong enough to prevent any slippage. If slight slippage is permitted, the floor is called partially composite.

Optimizing the design of composite floors was intensively addressed in the last twenty years. Many researchers tried different optimization techniques such as Nonlinear Programming (NLP), Artificial Neural Network (ANN), Genetic Algorithm (GA), Ant Colony (AC), and Harmony Search (HS).

In this regard, Balaur S. Dhillon and Chen-Hsing Kuo [1] carried out the first trial to optimize the design of composite, hybrid plate girders using generalized geometric programming (GGP) technique. Samer Hendawi and Dan M. Frangopol [2] implement the corrosion effects in reliability-based optimization of composite hybrid plate girders 
using time-independent reliability-based structural optimization (RBSO) approach. Hojjat Adeli and Hongjin Kim [3] optimized the design of composite beams according to the LRFD of the AISC using the integer-discrete Nonlinear Programming and then mixed the results using neural dynamics model. Hongjin Kim and Hojjat Adeli [4] used floating-point Genetic Algorithm to optimize the LRFD design of composite floors according to AISC. S. Kravanja and S. Silih [5] used the well-known Nonlinear Programming (NLP) approach to optimize the design of both trusses and beams composite floors according to Eurocode. Christopher M. Foley and Warren K. Lucas [6] used Genetic Algorithm (GA) to optimize the design of both composite and noncomposite floors according to AISC considering vibration criteria. M. Veljkovic and B. Johansson [7] suggested some modifications in the design equations of Eurocode 3 to optimize the design of cylinder hybrid beams considering fatigue effect based on experimental and theoretical studies. Uroš Klanšek and Stojan Kravanja [8] considered the direct production costs including material costs, power consumption, and labor costs. Uroš Klanšek and Stojan Kravanja [9], in the 2nd part of their research, optimized the design of composite floors using Nonlinear Programming (NLP) approach. S. Kravanja and U. Klanšek [10] suggested an optimization technique for both truss and beam composite floors according to Eurocode using Nonlinear Programming (NLP). Ahmed B. Senouci and Mohammed S. Al-Ansari [11] presented a Genetic Algorithm (GA) model to optimize the design of composite beams according to the LRFD of the AISC considering the effect of span and loads. Kaveh and A. Shakouri Mahmud Abadi [12] optimized the design of composite floors according to the LRFD of the AISC using both traditional and improved Harmony Search algorithm. Kaveh and M. Ahangaran [13] continued their previous research using social Harmony Search technique. Victoria E. Roşca et al. [14] presented an optimization technique for composite beams design according to EN-1994-1-1/2006 using Nonlinear Programming (NLP) approach. Blachowski and W. Gutkowski [15] estimated the minimum weight of steel in composite floors to satisfy the design requirements under human induced vibrations. Roland Abspoel and Frans Bijlaard [16] suggested a new optimized design strategy for both hybrid and nonhybrid plate girder based on experimental and theoretical studies. Andrew J. Unander [17] studied the design of composite floors statistically based on a database containing 640 existing buildings to estimate the range of the optimum steel weight per unit area of floor. Hamid Eskandari and Tahereh Korouzhdeh [18] used Matlab software to generate a database of 20,000 composite beams to produce a contour map of cost with respect to affecting parameters. Rong $\mathrm{He}$ et al. [19] investigated the effect of optimizing the composite floors of super tall buildings on their lateral stiffness and serviceability. Pavol Juhás [20] studied the fatigue failure mechanisms of thinwalled hybrid plate girders. Tahereh Korouzhdeh et al. [21] used Improved Ant Colony (IAC) technique to optimize the design of composite beams according to the LRFD of the AISC, and the research results indicated that the efficiency of the improved technique surpassed the original one. R. Silva and T. A. Rodrigues [22] modeled the composite beam using FEM to generate a database and then applied sequential linear programming technique to optimize the design. N. M. Yossef and S. Taher [23] used Genetic Algorithm (GA) technique to optimize the design of castellated beams in composite floors with respect to section dimensions and opening size. Tahereh Korouzhdeh and Hamid EskandariNaddaf [24] suggested a cost-safety optimization technique based on standardized formulation using LRFD design method, and the results were verified and compared with those from AI techniques. Yong-Bo Shaoa et al. [25] presented a theoretical study for strength and behavior of laterally unrestrained S690 high-strength steel hybrid girders with corrugated webs. Ebid [26] developed an equation to estimate the optimum weight of nonhybrid unstiffened composite steel beams using the GRG optimization technique. On the other hand, Saghir et al. [27] carried out a comprehensive experimental study for the mechanical characterization of FRP composite pipes. Katsamakas et al. [28] presented a FEM-based model to study the behavior of SRG-strengthened R/C beams. Gohari et al. [29] suggested a new analytical solution for elastic flexure of thick multilayered composite hybrid plates resting on Winkler elastic foundation in air and water.

\section{Objective}

Despite the previous efforts in optimizing the design of hybrid composite floors beams, there are still some points that need further investigation such as the following:

Consideration of unit weight cost of each type of steel part

Consideration of construction sequence effect (shored or unshored)

Presentation of optimization results in simple and practical equations

The objective of this research is to cover the abovementioned points to end up with a set of equations to determine the optimum section dimensions at any location along the hybrid composite beam. This research is concerned with the weight optimization of the steel part excluding the shear connectors design.

\section{Methodology}

This research program is divided into two main phases. The first phase is concerned with generating a database of optimized composite beams, and the second phase is concerned with developing predictive models to predict the optimum cross section dimensions of the composite beam based on its configurations using the generated optimized dataset from the first phase. The detailed descriptions of each phase are provided in this section.

3.1. Phase 1: Generating the Optimized Database. The main difficulty of optimizing the hybrid composite beam is the 
large number of parameters that affect the design. These parameters could be classified as follows:

Geometrical parameters: beams section dimensions, span, spacing, and type of supports

Material parameters: steel grads of web and flanges, slab concrete strength, and creep factor

Loading parameters: values of dead, superimposed, and live loads

Construction parameters: level of shoring (fully shored, partially shored, and unshored)

Cost parameters: the unit cost of steel web and flanges besides the unit cost of the concrete

In order to organize and facilitate the research, the following assumptions are considered:

To reduce the number of the considered parameters, beams span, spacing, type of support, and load value will be presented using one parameter which is the maximum total bending moment on the beam $(M)$

The characteristic strength of concrete cube $\left(F_{\mathrm{cu}}\right)$ is limited between 25 and $45 \mathrm{MPa}$, and the allowable compressive stress in the concrete deck is $0.25 F_{\mathrm{cu}}$

The ratio between elastic modulus of steel and concrete (modular ratio) $(n)$ is calculated based on the concrete strength considering the creep factor equal to 2.0

The considered steel grades have ultimate strength of $240,360,460$, and $690 \mathrm{MPa}$

Factor $a$ presents the ratio between the bending moment $M o$ of the initial stage (steel section only) and the total bending moment $M$ (i.e., $\alpha=\mathrm{Mo} / \mathrm{M}$ ). If $\alpha=0$, the initial bending moment is zero, and the beam is fully shored. On the other hand, if $\alpha=1$, the initial bending moment equals the total bending moment, and the beam is noncomposite:

Factor $\eta$ presents the ratio between the unit cost of flanges steel and the web steel $\left(\eta=C_{f} / C_{w}\right)$.

The optimization will consider the unshored construction sequence as reference to optimize the shored condition.

Effective width of concrete deck is considered as 12 times its thickness. Accordingly, beam span and spacing between beams shall not be less than 48 and 12 times deck thickness, respectively.

Due to construction limitations, the minimum thickness of concrete deck is considered to be $10 \mathrm{~cm}$.

For steel section, the minimum compression flange area is considered as $20 \%$ of the tension flange area.

The considered range of total bending moment $M$ is between 1500 and $50000 \mathrm{~cm}$.ton.

The units considered in all calculations and equations are ton and $\mathrm{cm}$.

Generally, the design of composite beam is divided into two phases: the first before concrete hardening and the second after concrete hardening. To calculate the stresses of each phase, properties of both steel and composite sections are calculated using an MS Excel sheet. Figure 1 illustrates the terms used in the calculations.

Calculation of section properties is based on the following assumptions:

Compression and tension steel flanges are modeled as steel areas $A_{s c}$ and $A_{s t}$, respectively, and act at their centers of gravity

Concrete deck is modeled as equivalent steel area $\left(A_{c}=12 t_{s} . T_{s} / 2 n\right)$ and acts in its center of gravity, where $2 n$ is the modular ratio considering creep factor

The web plate is modeled as rectangular area with height equal to distance between upper and lower plates centers and thickness equal to the minimum value that keeps the section in noncompacted category $\left(H_{s} / t_{w}=190 / \sqrt{ } F_{\mathrm{yw}}\right)$, where $\mathrm{F}_{\mathrm{yw}}$ is the yield stress of web steel in $\left(\right.$ ton $\left./ \mathrm{cm}^{2}\right)$ :

Thicknesses of steel plates are neglected, and hence $H \approx H_{\mathrm{s}}+t_{\mathrm{s}}$

Steel section cost $=C_{f} \cdot \gamma_{\mathrm{s}} . A_{\mathrm{sc}}+A_{\mathrm{st}}+A_{\mathrm{sw}} / \eta$, where $\gamma_{s}$ is the steel density

Since both $C_{f}$ and $\gamma_{s}$ are constants for considered case, the optimization issue is reduced to simple question, what is the combination of $A_{c}, A_{\mathrm{sc}}, A_{\mathrm{st}}$, and $H_{s}$ for a certain given bending moment that gives minimum value of $A_{\mathrm{sc}}+A_{\mathrm{st}}+A_{\mathrm{sw}} / \eta$ and maintains the stresses in the section below the allowable limits? To answer this question, both actual and allowable stresses must be calculated.

Since the section is classified as noncompacted section, there is no reduction in section properties due to local buckling, and hence the actual stresses for a certain phase equal the bending moment of this phase divided by the corresponding section elastic modulus. On the other hand, the allowable stress in concrete deck shall not exceed 0.25 $F_{\mathrm{cu}}$. Regarding the steel section, considering that the upper compression flange is kept braced out of plan till concrete deck hardening, where there will be no reduction in the allowable normal stress due to lateral torsional buckling, the allowable normal stress for noncompacted, nonhybrid section is $0.58 f_{y}$. For noncompacted, hybrid sections, AASHTO Section 10.53.2 [1] suggested a reduction factor $(R)$ to reduce the allowable stresses in the flanges. This reduction factor could be calculated as follows:

$$
R=1-\left[\frac{\beta \psi(1-\delta)^{2}(3-\psi+\delta \psi)}{6+\beta \psi(3-\psi)}\right],
$$

where $\psi$ is the distance from the neutral axis to the outer fiber of tension flange/steel section depth, $\beta$ is the web area/ tension flange area, and $\delta$ is the yield stress of web/yield stress of flanges.

In order to find the optimum combination of $A_{c}, A_{\mathrm{sc}}, A_{\mathrm{st}}$, and $H_{s}$ for a certain bending moment, an add-in tool to MS Excel software is used. The tool is called "Solver", and it can figure out the combination of certain variables' values that minimize or maximize the target function under certain governing conditions. It is based on a well-known 


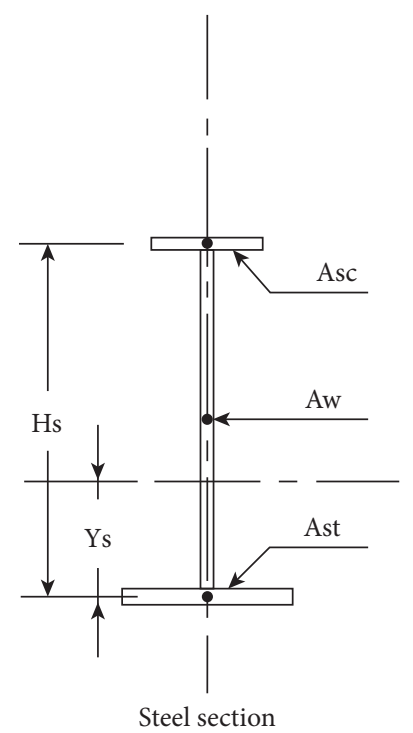

(a)

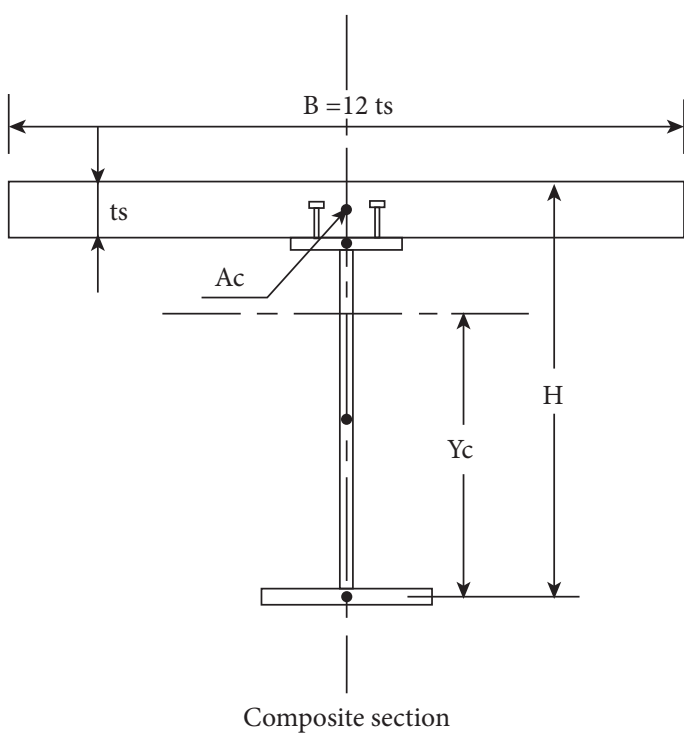

(b)

FIgURE 1: The considered built-up composite beam section. (a) Steel section. (b) Composite section.

mathematical technique called "Generalized Reduced Gradient (GRG) Nonlinear Solving." This technique depends on changing the values of the affecting variables gradually while monitoring the governing conditions until the partial derivatives of the target function equal zero. In addition to the basic GRG technique, "Solver" tool enhances the searching performance by using automatic scaling for research intervals which adjusts the magnitude of change in each variable value for each iteration step.

Using the previously described "Solver" tool, the optimum combination of $A_{c}, A_{\mathrm{sc}}, A_{\mathrm{st}}$, and $H_{s}$ values is investigated for certain bending moment under the following governing conditions:

Stress in upper plate shall not exceed $0.58 F_{\mathrm{yf}} R$ during the $1^{\text {st }}$ phase

Summation of stress in upper plate shall not exceed $0.58 F_{\mathrm{yf}} R$ for both $1^{\text {st }}$ and $2^{\text {nd }}$ phases

Summation of stress in lower plate shall not exceed 0.58 $\mathrm{F}_{\mathrm{yf}} R$ for both $1^{\text {st }}$ and $2^{\text {nd }}$ phases

Stress in concrete deck shall not exceed $0.25 F_{\text {cu }}$ during the $2^{\text {nd }}$ phase

3.2. Phase 2: Developing the Predictive Models. A complete database of 504 records is generated using the previous discussed technique. The database was designed to cover the following variables' ranges:

Total bending moment (cm.ton) $[M=1500,3000,6000$, $12500,25000,50000]$

Initial to total bending moment $\left[\alpha=M_{\mathrm{o}} / M=0.00,0.25\right.$, $0.50,1.00]$

Web and flange yield stress $\left(t / \mathrm{cm}^{2}\right)[2.4 / 2.4,2.4 / 3.6$, 3.6/3.6, 3.6/4.6, 4.6/4.6, 4.6/6.9, 6.9/6.9]
Flange steel to web steel unit cost $\left[\eta=C_{\mathrm{f}} / C_{\mathrm{w}}=1.00\right.$, $1.25,1.50]$

Each record contains the values of $M, a, \eta, F_{\mathrm{yw}}, F_{\mathrm{yf}}$, and $F \mathrm{cu}$ and the corresponding optimized values of $H_{s}, A_{\mathrm{sc}}, A_{\mathrm{sw}}$, $A_{\mathrm{st}}$, and $t_{\mathrm{s}}$. The complete database is presented in Table 1.

Finally, the generated database was used to find the correlations between inputs and outputs using both Nonlinear Regression (NLR) and Artificial Neural Network (ANN).

The generated database was divided into a training set (354 records) and validation set (150 records) as presented in Table 1 . The training set is used to develop the predictive models while the validation set is used to test the efficiency (validity) of the developed models. Tables 2 and 3 summarize their statistical characteristics and the Pearson correlation matrix. Finally, Figure 2 shows the histograms for both inputs and outputs. The results of all developed models are summarized in Table 4.

\section{Predicting the Optimized Cross Section}

4.1. Model (1): Using NLR Technique. Studying the relation shapes between each input and output graphically indicated that power function is the suitable choice to describe the correlations with $\mathrm{M}, F_{\mathrm{yw}}$, and $F_{\mathrm{yf}}$, while exponential function is the suitable choice to describe the correlations with $a$ and $\eta$. Hence, the proposed general formula for these correlations is

$$
\text { Output }=x_{1} \cdot(M)^{x_{2}} \cdot\left(F_{y f}\right)^{x_{3}} \cdot\left(F_{y w}\right)^{x_{4}} \cdot e^{\alpha x_{5}} \cdot e^{\eta x_{6}} .
$$

The same add-in tool, "Solver," was used to figure out the values of $x_{2}$ to $x_{6}$ for each output by minimizing the "Sum of Squared Errors" (SSE), while the value of $x_{1}$ was used to adjust the function bias (the ratio between actual and 


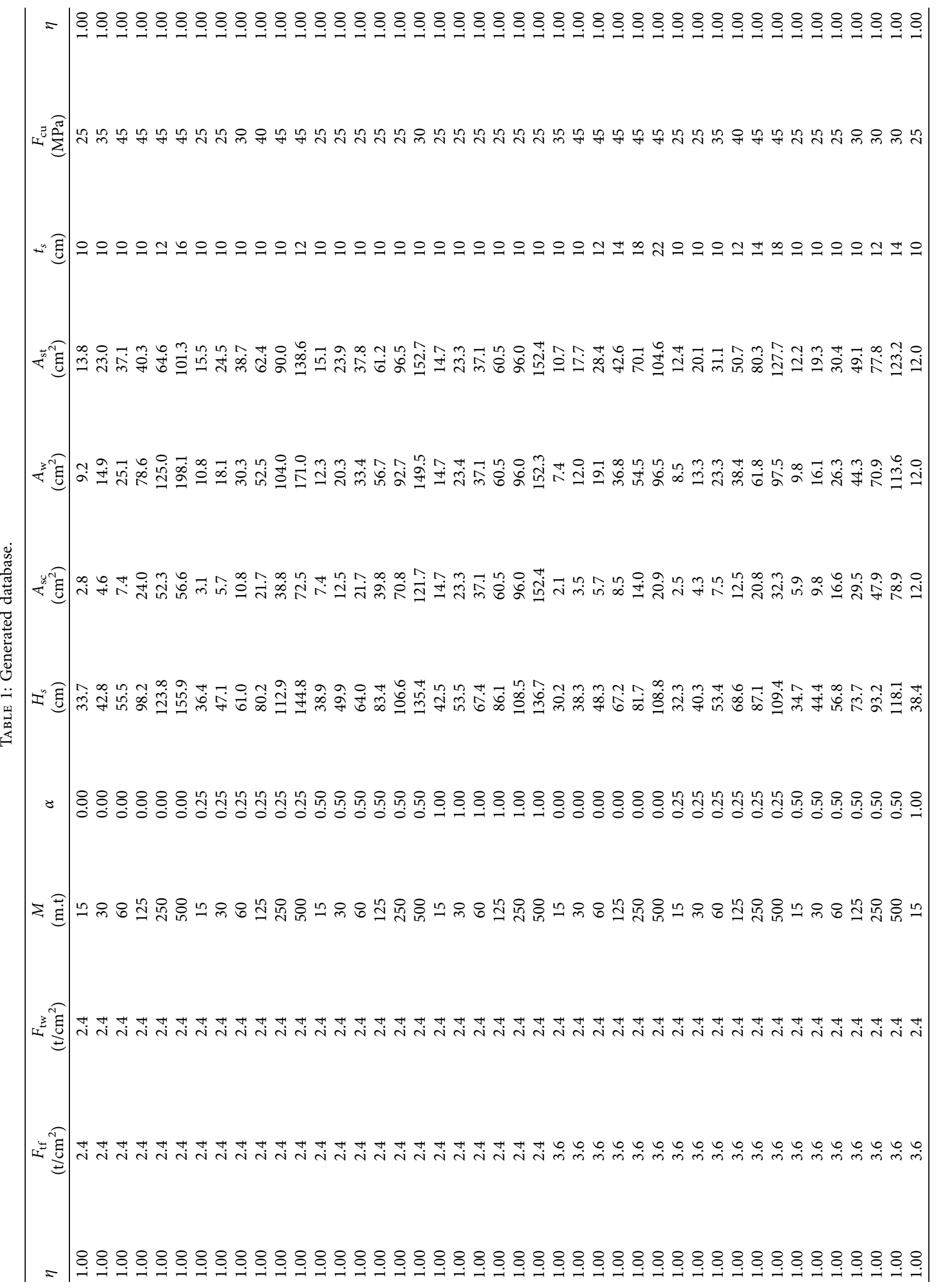




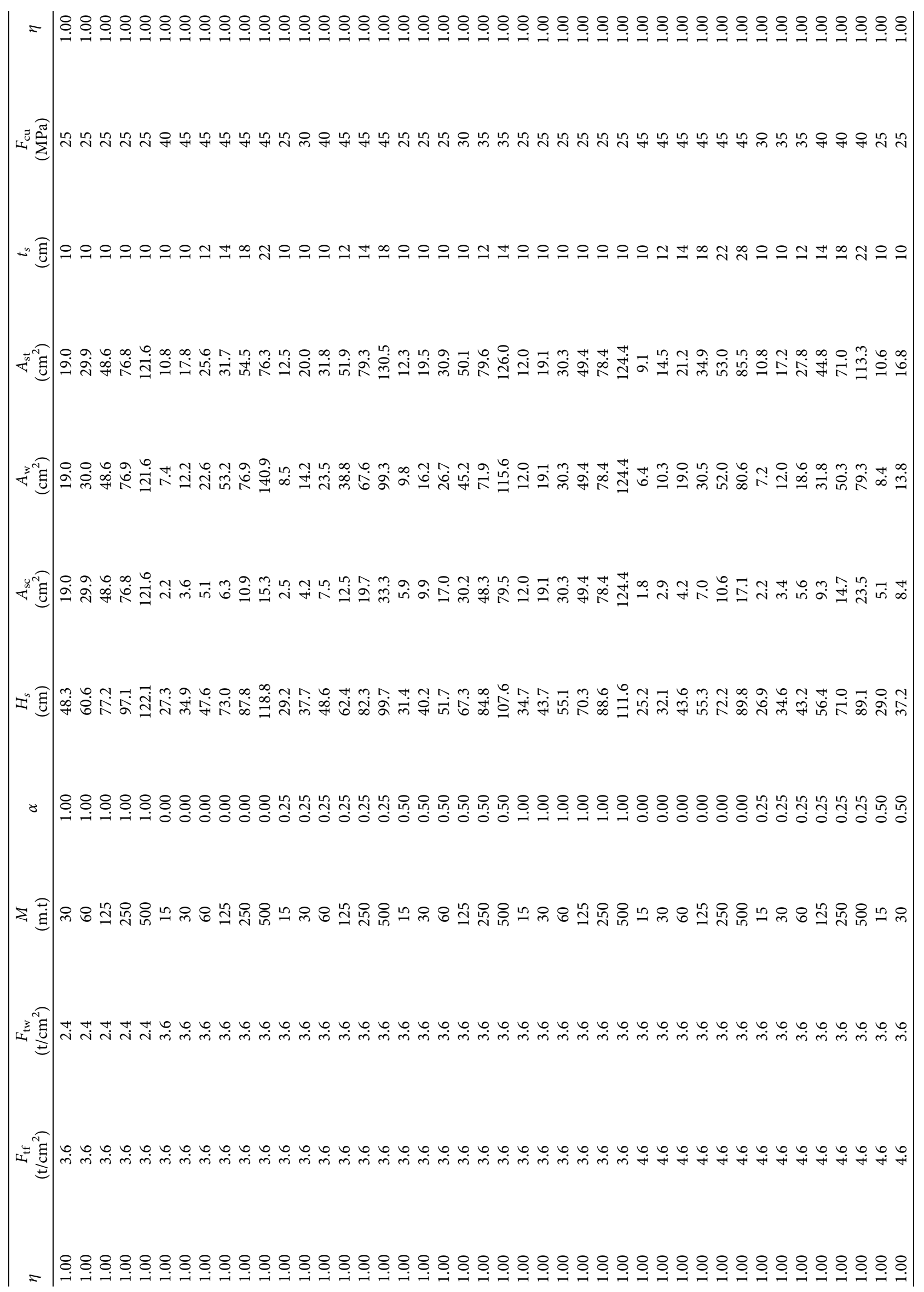


= \& \& \& \& \& \& \& \& \& \& \& \& \& \& \& \& \& \& \& \& \& \& \& \& \& \& \& \& \& \& \& \& \& \& \& \& \& \& \& \& \&

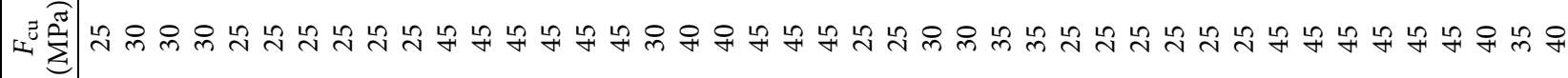

๘

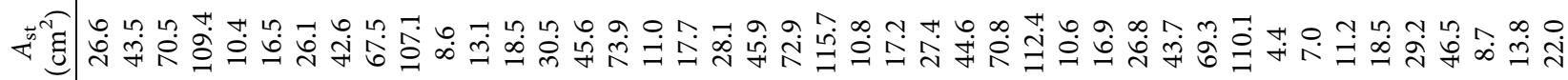

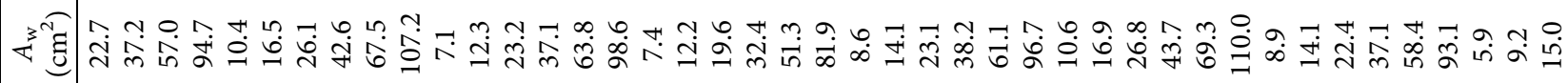

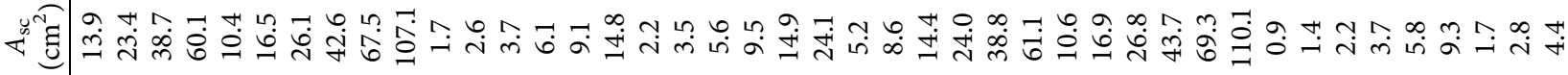

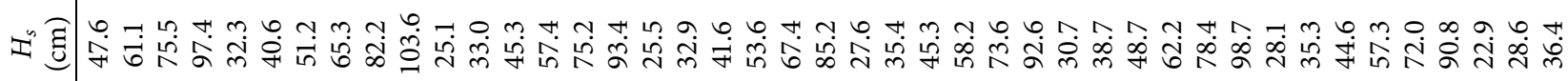

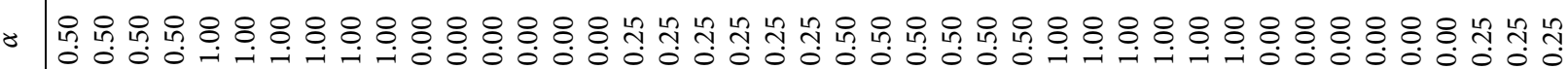

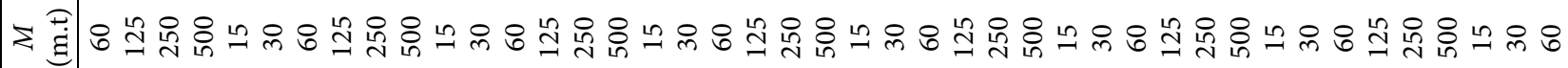

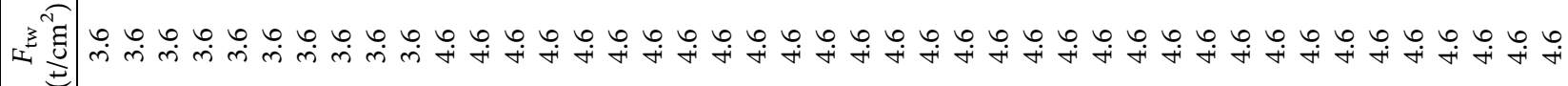

L

$=$ = \& \& \& \& \& \& \& \& \& \& \& \& \& \& \& \& \& \& \& \& \& \& \& \& \& \& \& \& \& \& \& \& \& \& \& \& \& \& \& \& \& \& 


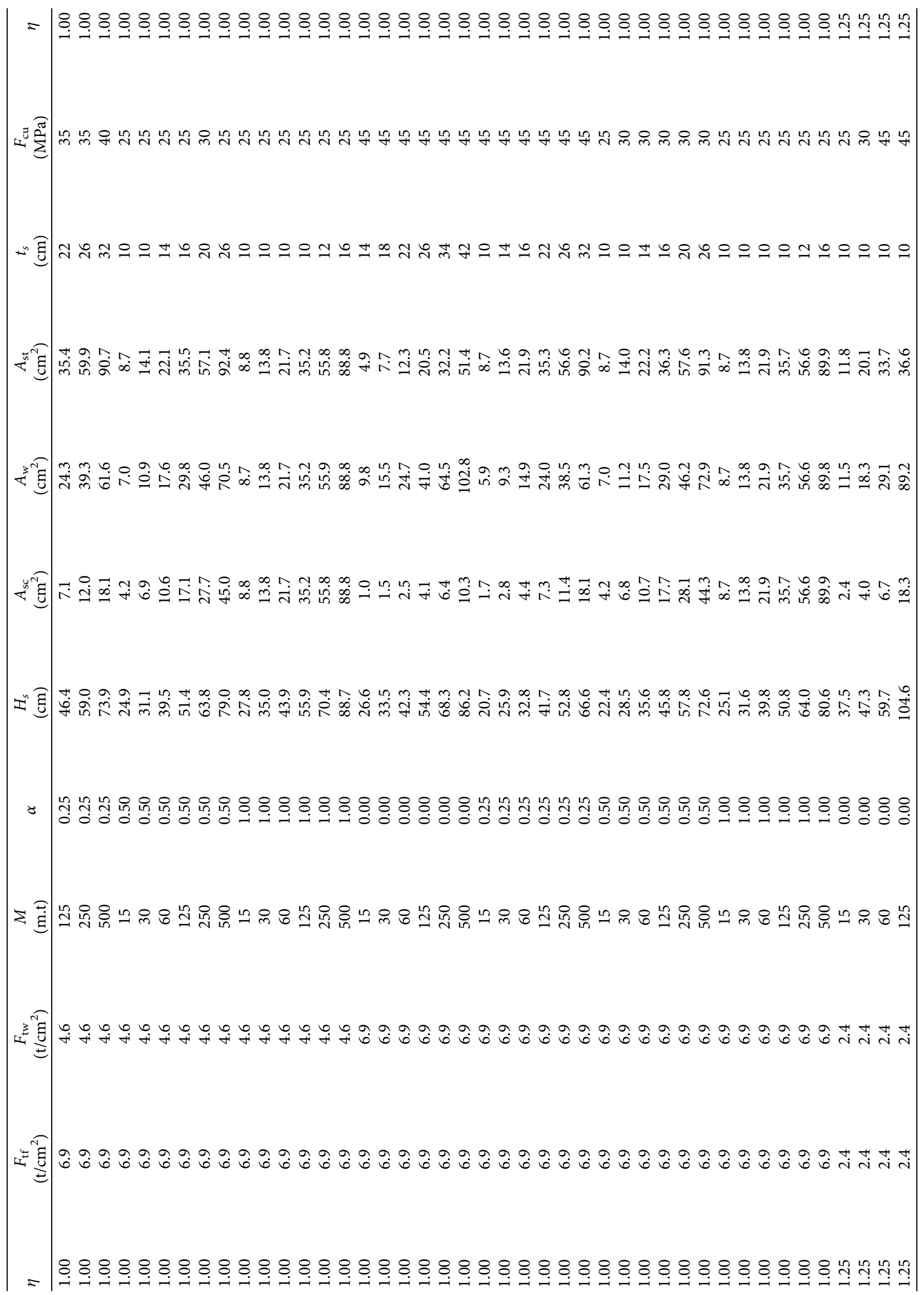




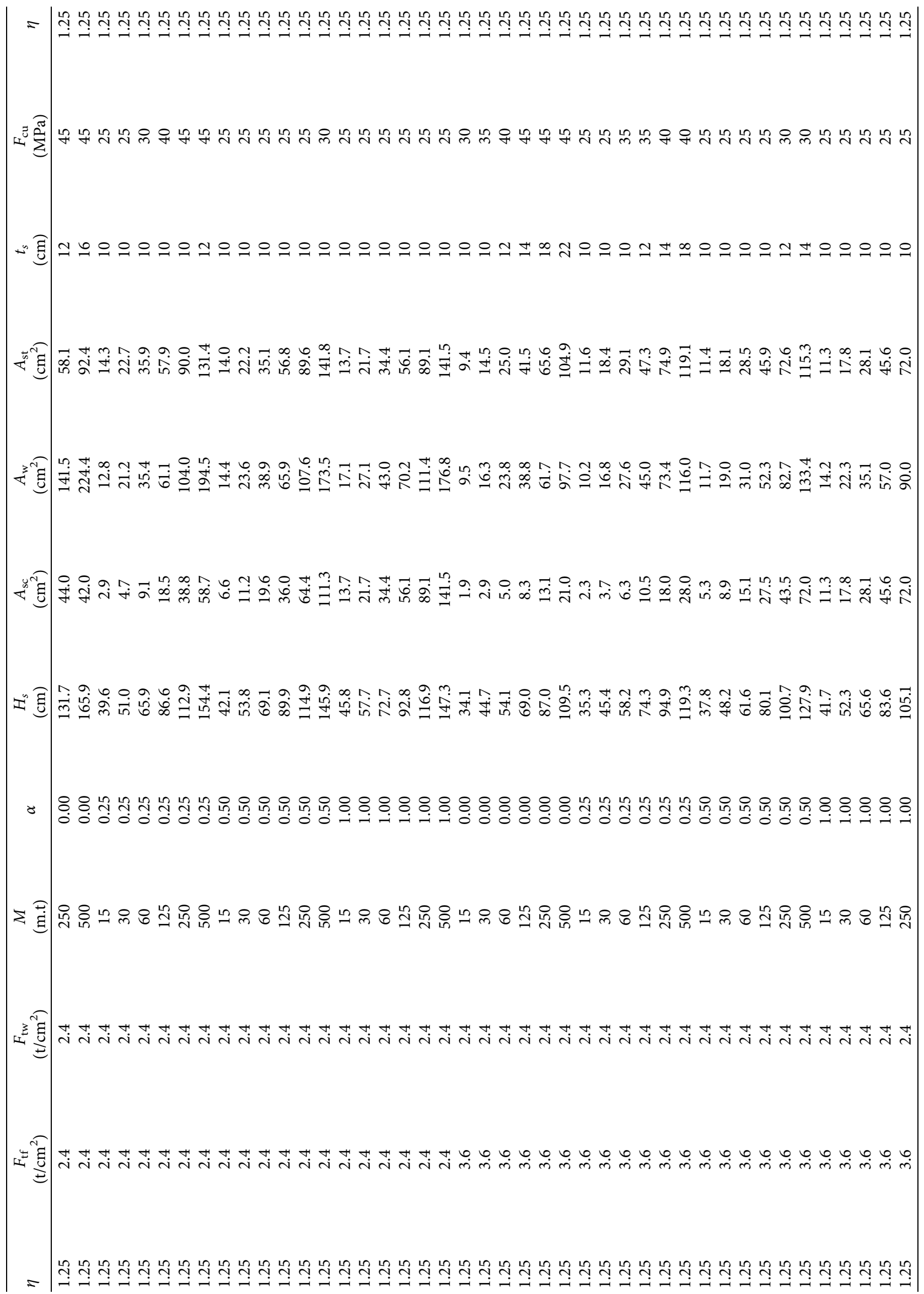




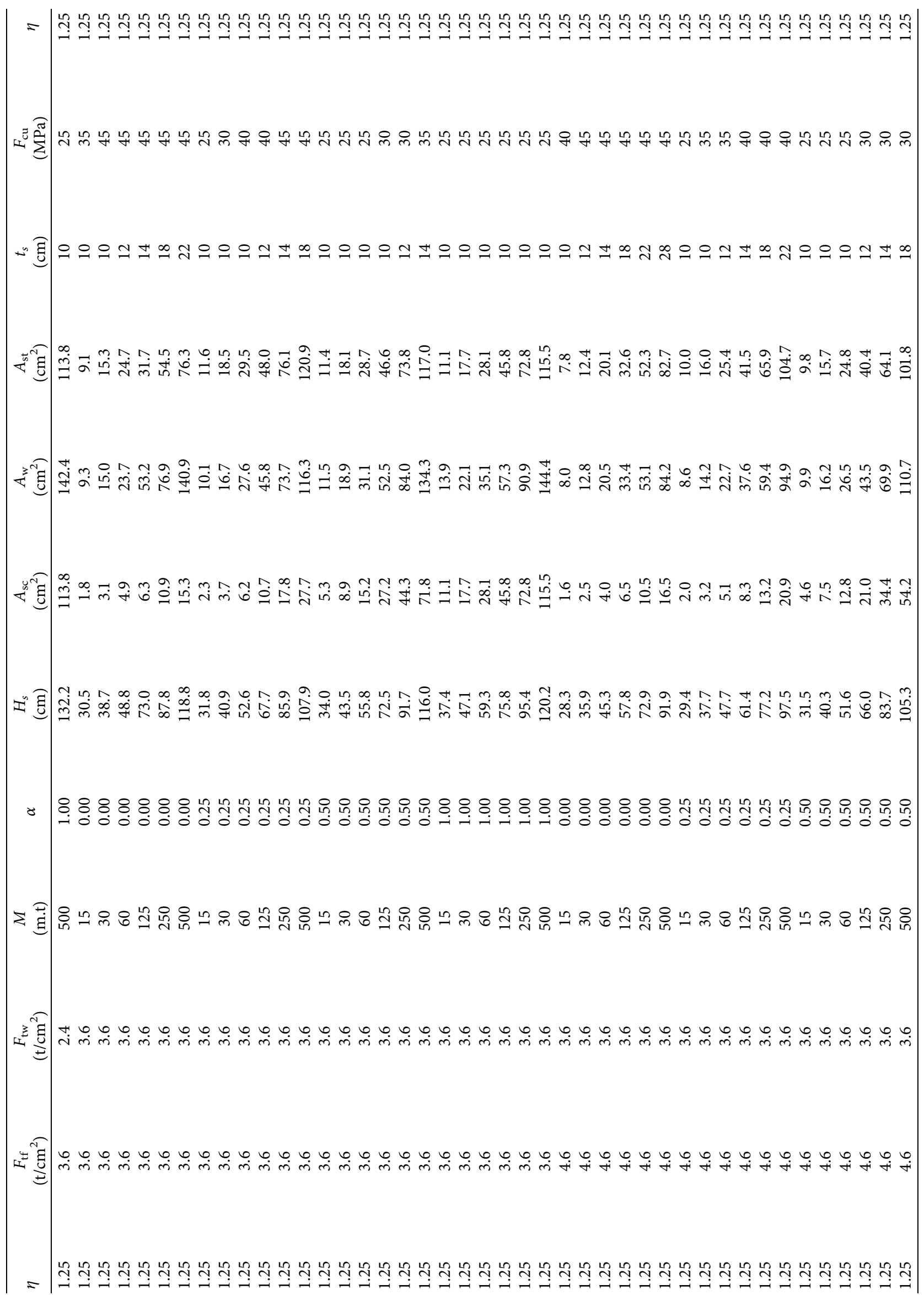




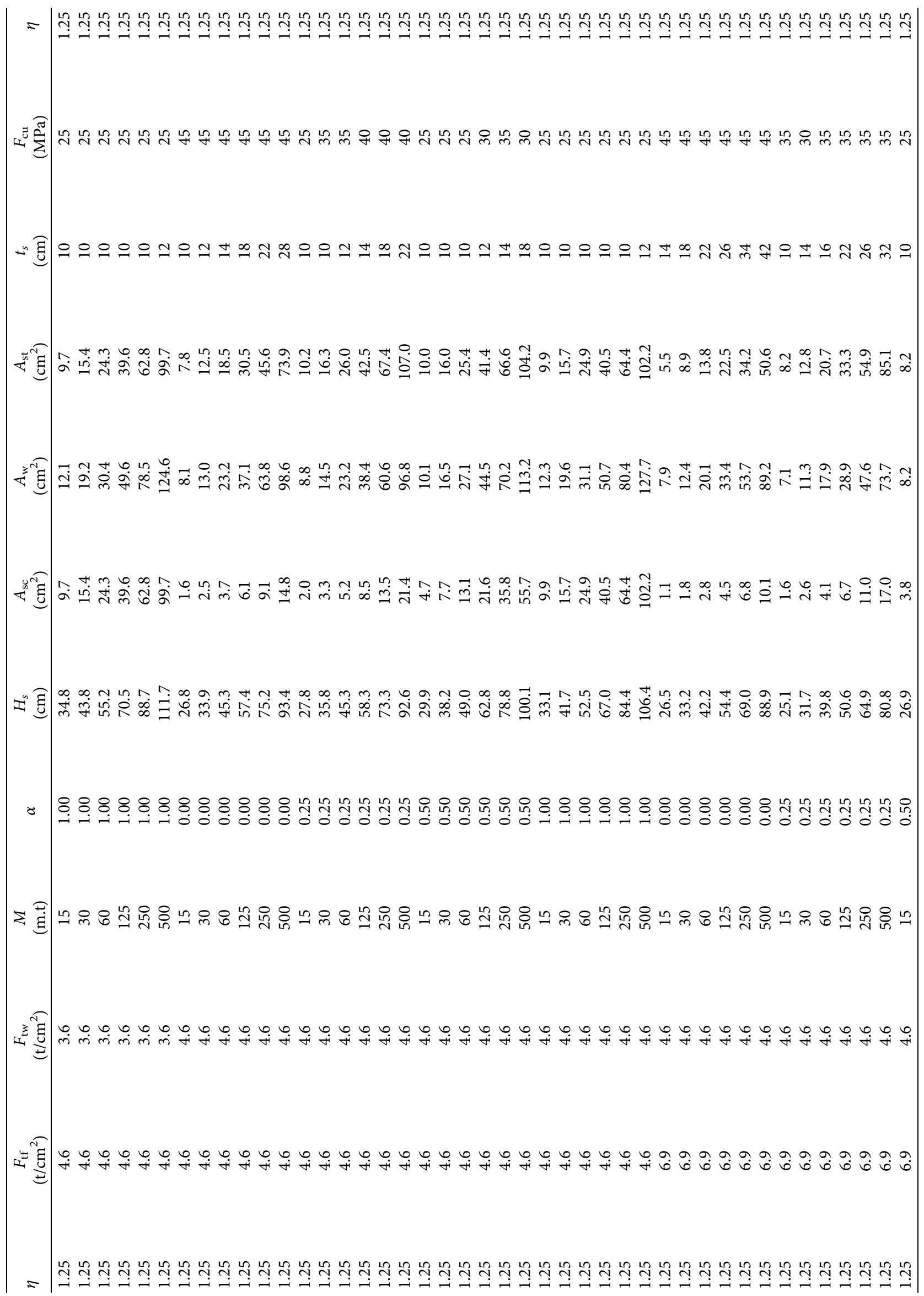




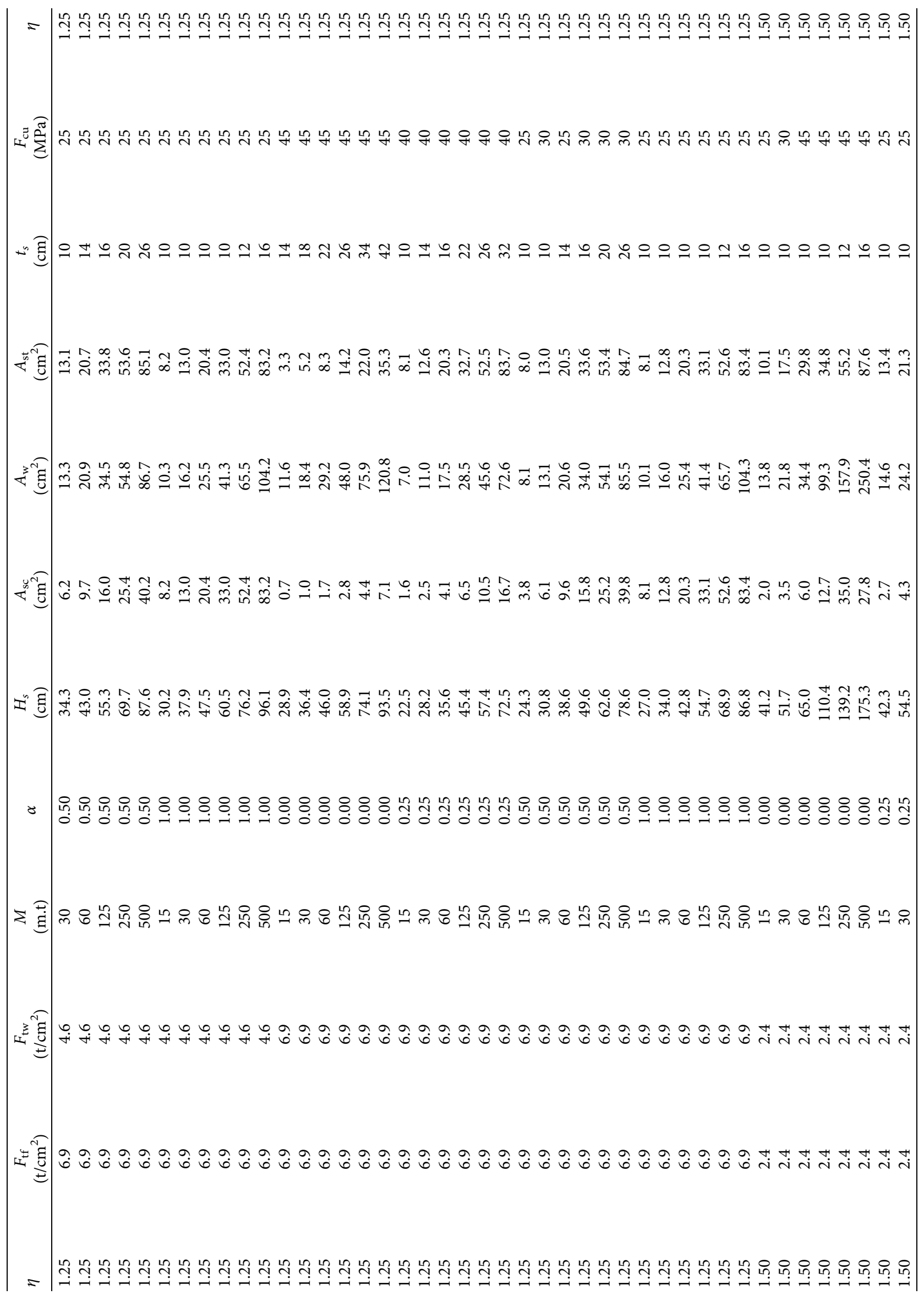




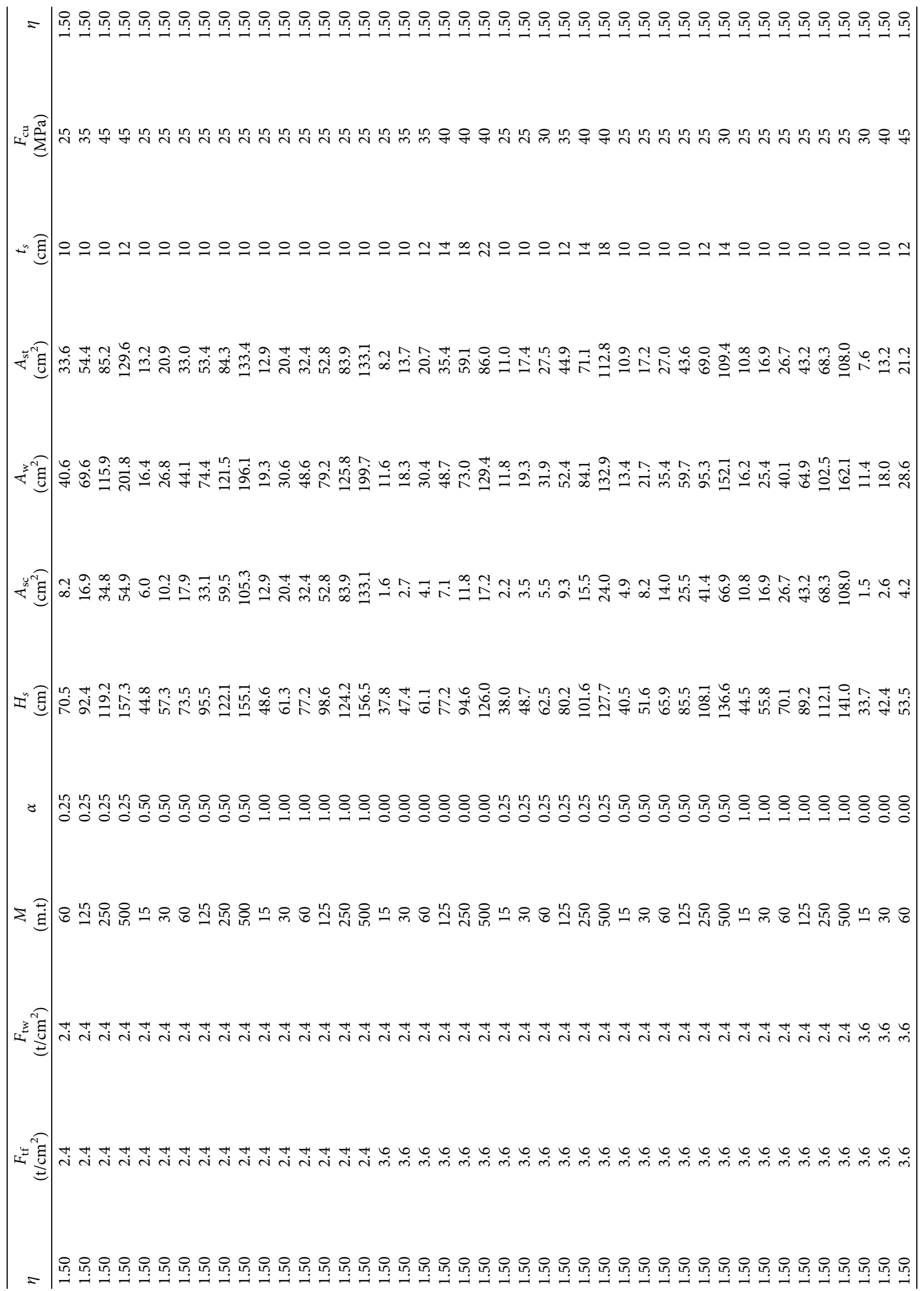




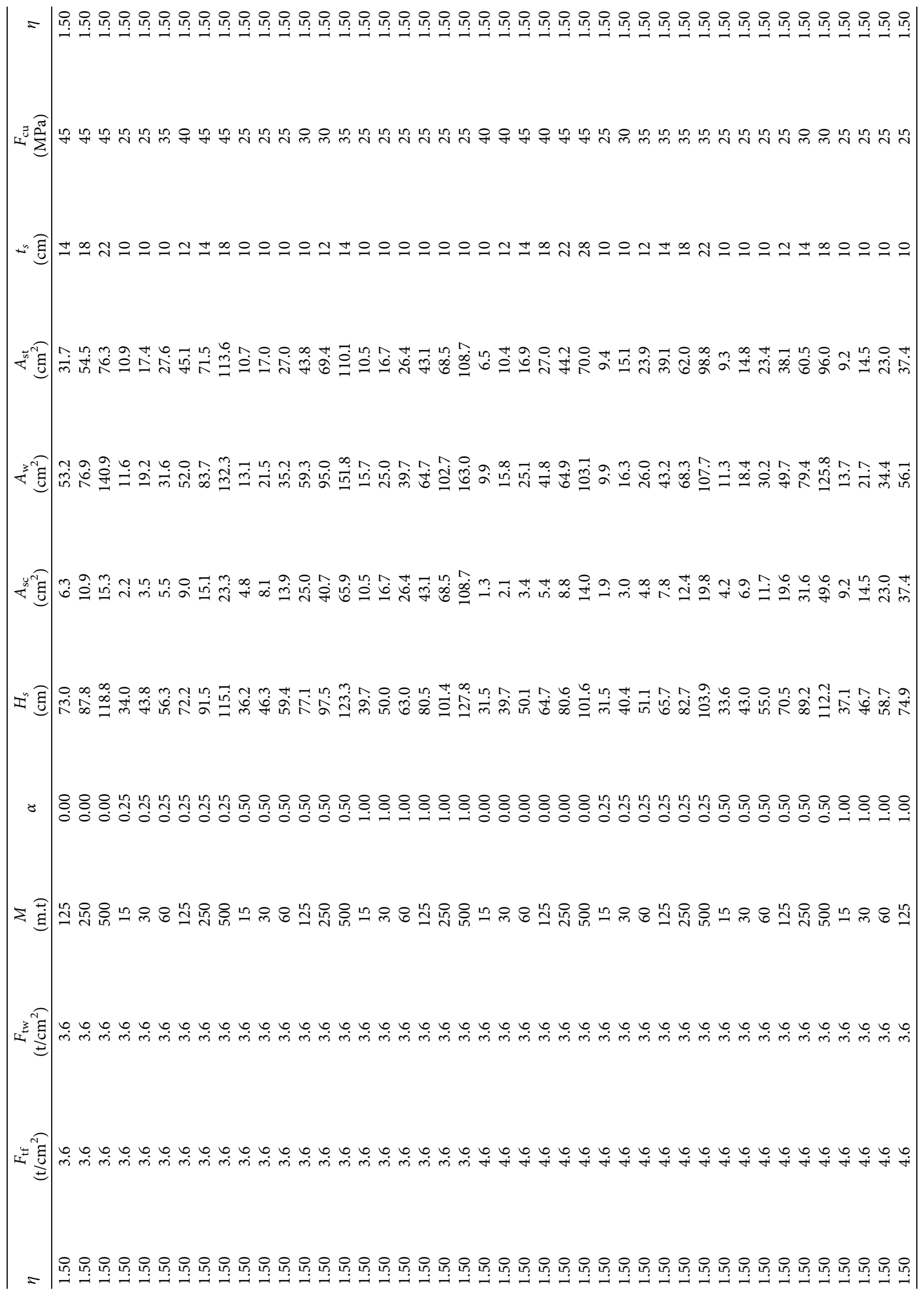




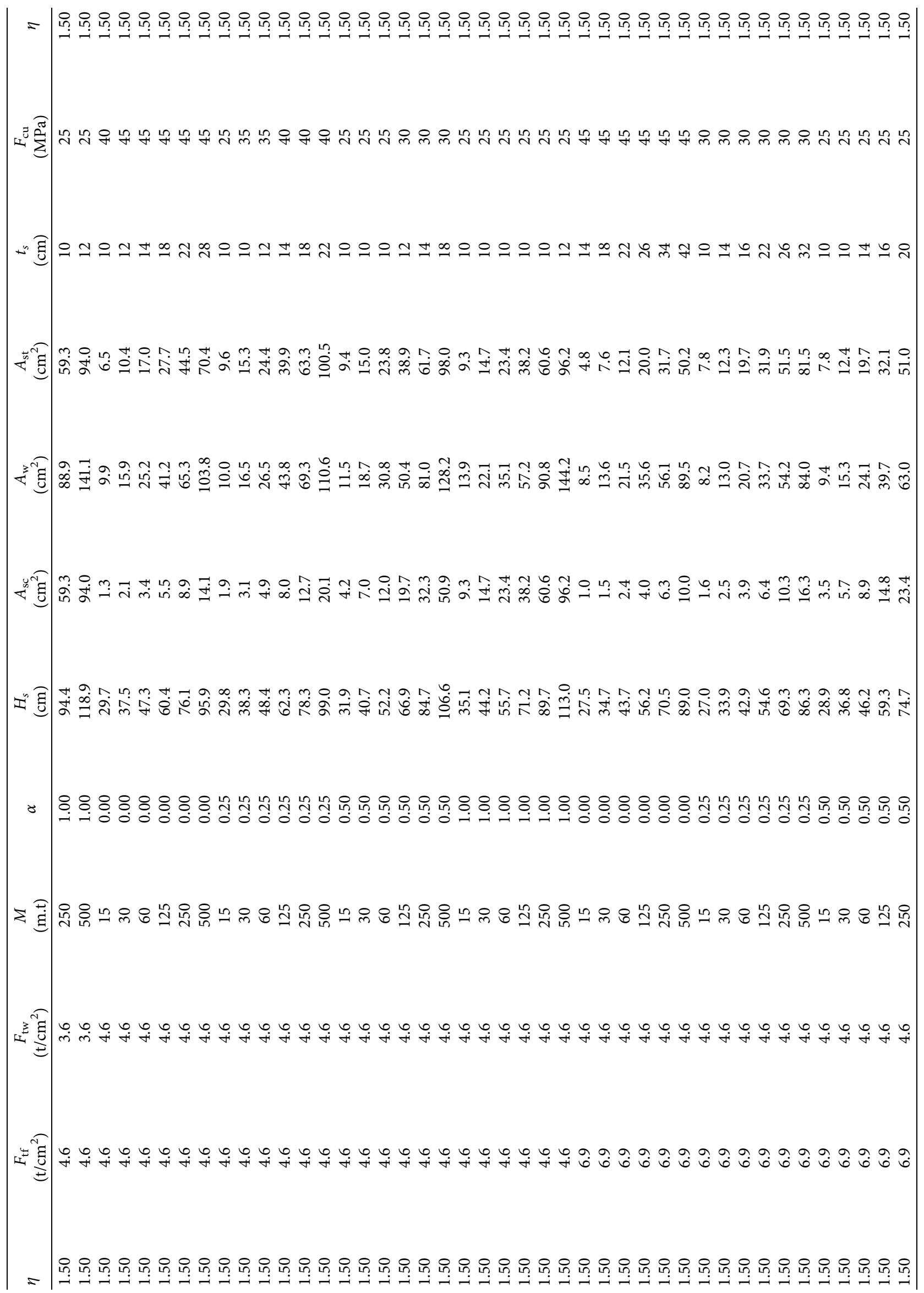




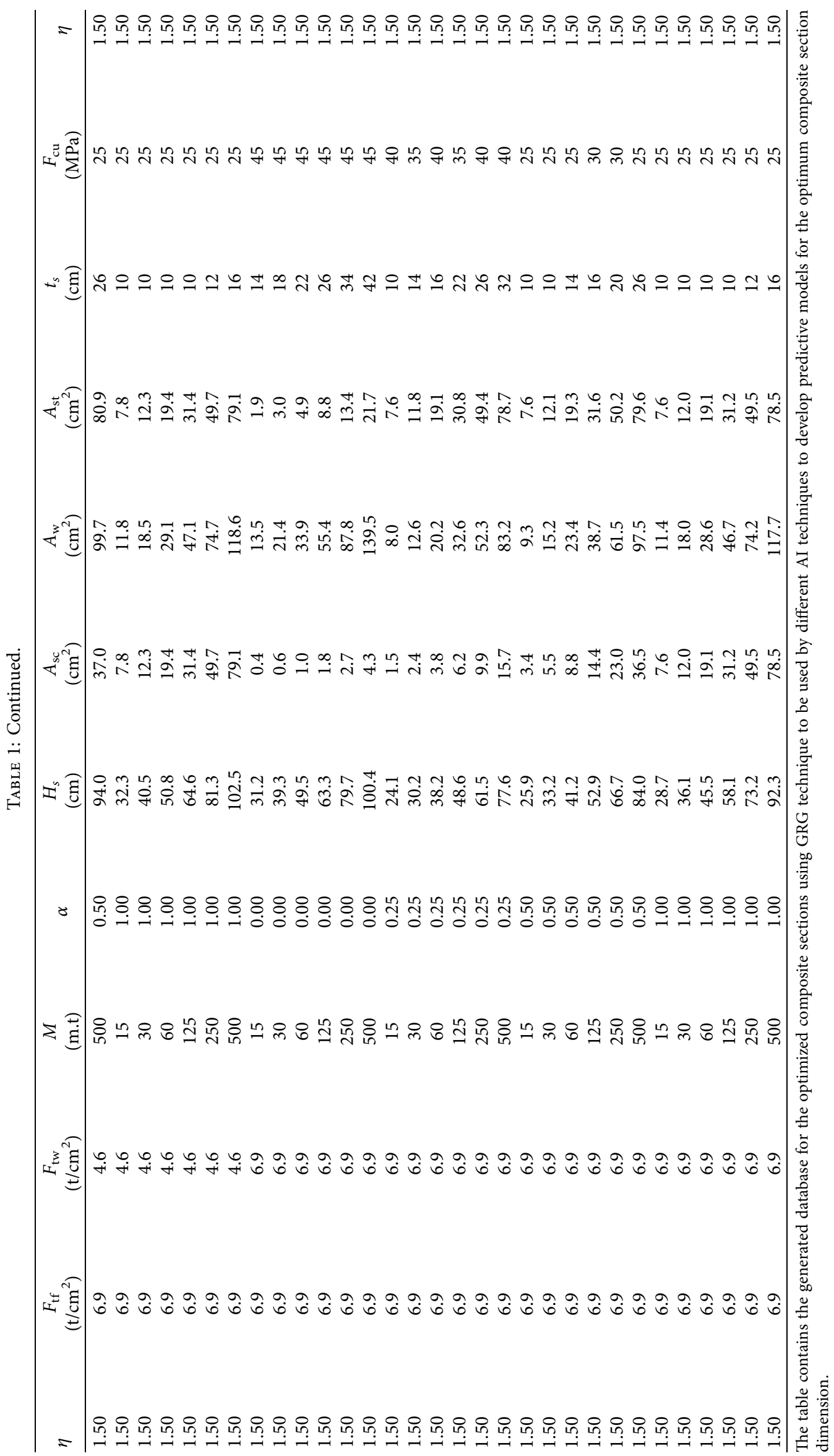




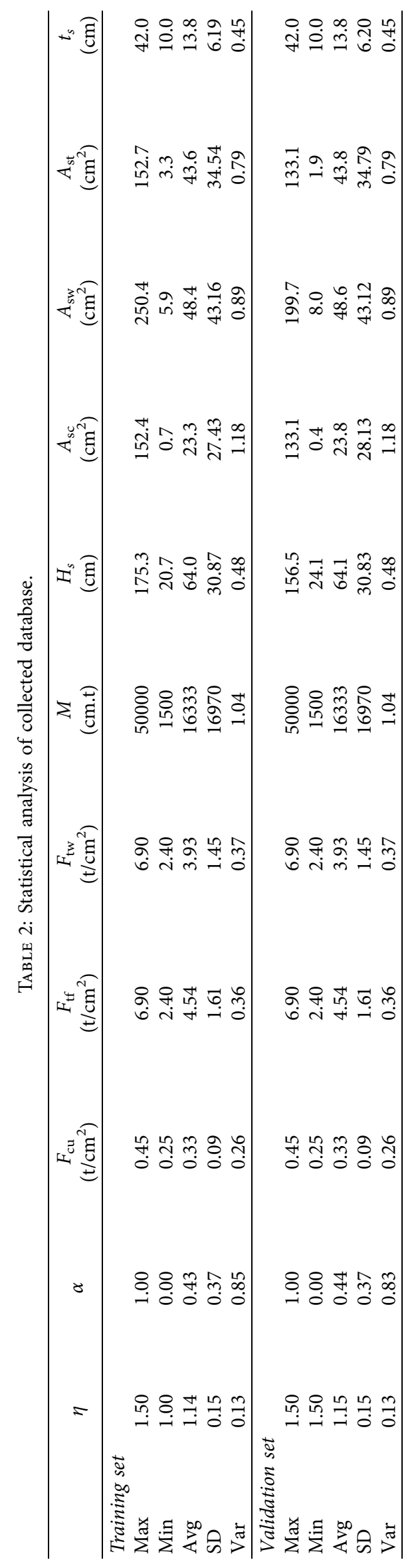


TABLE 3: Pearson correlation matrix.

\begin{tabular}{|c|c|c|c|c|c|c|c|c|c|c|c|}
\hline & $\eta$ & $\alpha$ & $F_{\mathrm{cu}}$ & $F_{\mathrm{tf}}$ & $F_{\mathrm{tw}}$ & $M$ & $H_{s}$ & $A_{\mathrm{sc}}$ & $A_{\mathrm{sw}}$ & $A_{\text {st }}$ & $t_{s}$ \\
\hline$\eta$ & 1.00 & & & & & & & & & & \\
\hline$\alpha$ & 0.00 & 1.00 & & & & & & & & & \\
\hline$F_{c u}$ & -0.10 & -0.79 & 1.00 & & & & & & & & \\
\hline$F_{t f}$ & 0.00 & 0.00 & 0.09 & 1.00 & & & & & & & \\
\hline$F_{t w}$ & 0.00 & 0.00 & 0.13 & 0.85 & 1.00 & & & & & & \\
\hline$M$ & 0.00 & 0.00 & 0.20 & 0.00 & 0.00 & 1.00 & & & & & \\
\hline$H_{s}$ & 0.11 & 0.08 & 0.13 & -0.37 & -0.34 & 0.84 & 1.00 & & & & \\
\hline$A_{\mathrm{sc}}$ & -0.06 & 0.54 & -0.32 & -0.22 & -0.18 & 0.64 & 0.73 & 1.00 & & & \\
\hline$A_{\mathrm{sw}}$ & 0.12 & 0.06 & 0.15 & -0.24 & -0.19 & 0.89 & 0.97 & 0.73 & 1.00 & & \\
\hline$A_{\text {st }}$ & -0.07 & 0.11 & 0.09 & -0.24 & -0.21 & 0.91 & 0.90 & 0.77 & 0.89 & 1.00 & \\
\hline$T_{s}$ & 0.00 & -0.43 & 0.52 & 0.46 & 0.39 & 0.54 & 0.23 & -0.12 & 0.29 & 0.25 & 1.00 \\
\hline
\end{tabular}
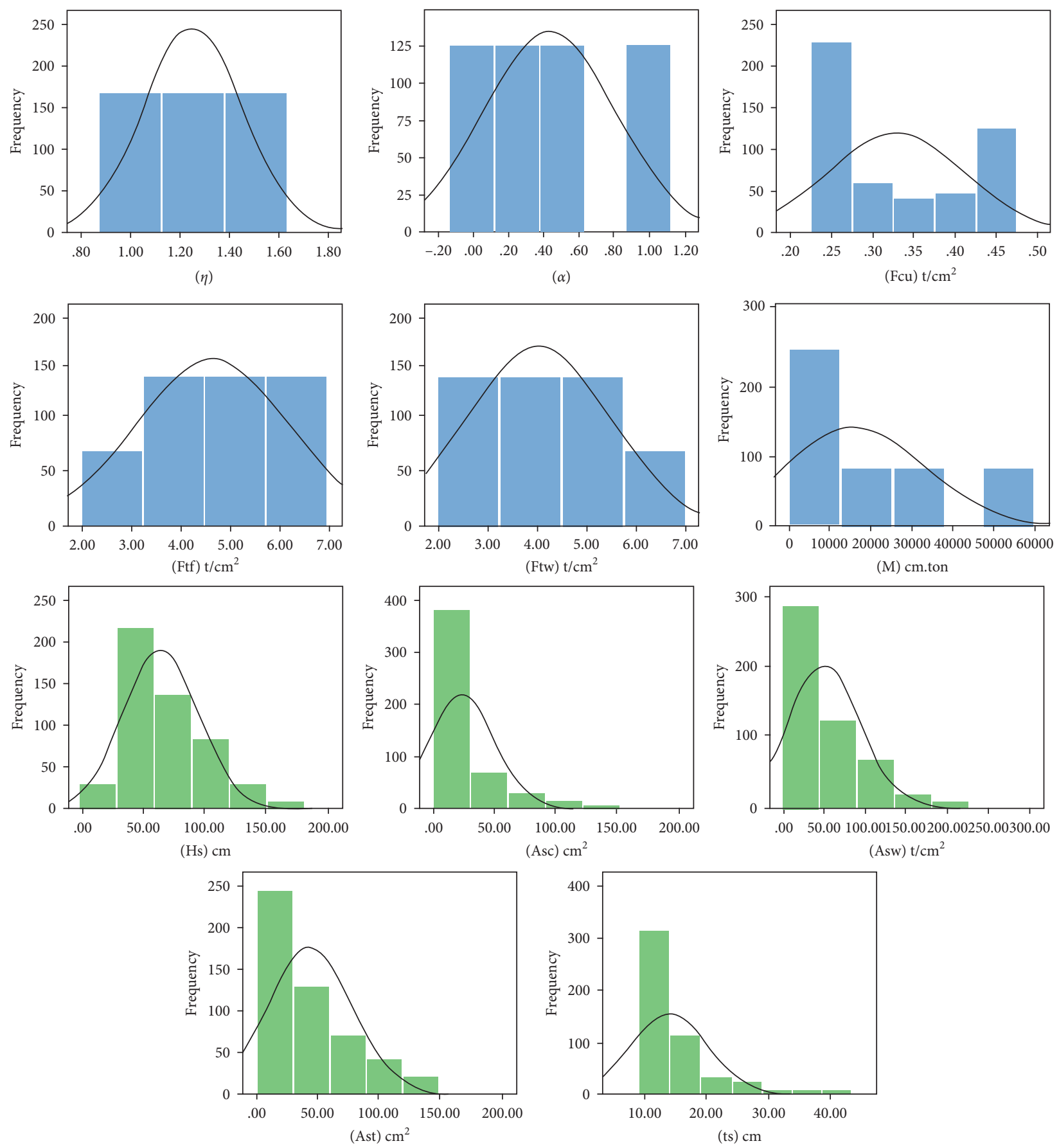

FIGURE 2: Distribution histograms for inputs (in blue) and outputs (in green). 
TABLE 4: Accuracies of developed models.

\begin{tabular}{lcccc}
\hline & \multicolumn{2}{c}{ NLR } & \multicolumn{2}{c}{ ANN } \\
& Error \% & $R^{2}$ & Error \% & $R^{2}$ \\
\hline$H_{s}$ & 8.8 & 0.966 & 6.7 & 0.979 \\
$A_{s c}$ & 27.4 & 0.941 & 16.0 & 0.982 \\
$A_{s w}$ & 19.1 & 0.950 & 12.2 & 0.980 \\
$A_{s t}$ & 18.1 & 0.950 & 11.9 & 0.977 \\
$t_{s}$ & 5.6 & 0.991 & 7.0 & 0.974 \\
\hline
\end{tabular}

calculated values). Applying the previously described methodology led to the following formulas:

$$
\begin{aligned}
H_{s} & =5.0 e^{\alpha+3 \eta / 12} \sqrt[3]{\frac{M}{F_{y f} F_{y w}},} \\
A_{s c} & =0.08 e^{(4 \alpha-\eta) / 3} \sqrt{\left(\frac{M}{F_{y f}}\right)^{2}}, \\
A_{s w} & =0.11 e^{(\alpha+3 \eta) / 6} \sqrt[\beta]{\left(\frac{M}{F_{y f}}\right)^{2}}, \\
A_{s t} & =0.22 e^{(\alpha-\eta) / 4^{3}} \sqrt{\left(\frac{M^{2}}{F_{y f} F_{y w}}\right)}, \\
t s & =0.16 e^{-\alpha} F_{y f} \sqrt[3]{M} \geq 10 \mathrm{~cm} .
\end{aligned}
$$

This technique showed fair level of accuracy where error $\%$ and $R^{2}$ values were $8.8 \%, 0.966 ; 27.4 \%, 0.941 ; 19.1 \%, 0.950$; $18.1 \%, 0.950$; and $5.6 \%, 0.991$ for $H_{s}, A_{\mathrm{sc}}, A_{\mathrm{sw}}, A_{\mathrm{st}}$, and $t_{s}$, respectively, as shown in Figures 3-7. Figures 3(a) to 7(a) presents the correlations between optimized and calculated values.

4.2. Model (2): Using ANN Technique. Artificial Neural Network (ANN) is a type of soft computing that is fashioned to simulate the way the human brain analyzes and processes information. ANN consists of a number of nodes (neurons) arranged in layers. The first layer is called "input layer," the last one is called "output layer," and all intermediate layers are "hidden layers." All neurons of a certain layer are connected to all neurons of the nest and previous layers by "links." Each link has a weight representing the relation strength between the connected neurons, and each neuron has an "activation function" to convert the summation of inputs into outputs. The prediction process, "forward propagation," starts by normalizing the input values (scaling them to lie within $(0,1)$ or $(-1,1)$ according to type of activation function), and then the normalized values are introduced to the neurons of the input layer. These values are transferred to the neurons of the first hidden layer through the links. The input of each neuron in the hidden layer is the summation of each connected neuron from the previous layer multiplied by the corresponding link weight, and the output of this neuron is the results of applying the activation function to the summation of inputs. This process propagates from hidden layer to the next till the output layer. The output of the output layer is the normalized values of the prediction; hence, these values are denormalized (scaled back to their original values) to get the ANN predicted values. Prediction accuracy depends on the learning ability of the ANN (adjusting the weights of the links). This process is carried out using a technique called "backward propagation" where the error (difference between predicted value and correct value) is distributed on the links of the previous layer based on the weight of each link, and then the weight of each link is adjusted according to its error share. This process propagates from the last hidden layer to the input layer.

A backward propagation ANN with two hidden layers and (Hypertan) activation function was used to predict the same output values. The used network layout and its connection weights are illustrated in Figure 8 and Table 5. Error $\%$ and $R^{2}$ values were $6.7 \%$ and 0.979 for $H_{\mathrm{s}}$ in Figure 3, $16.0 \%$ and 0.982 for $A_{\mathrm{sc}}$ in Figure $4,12.2 \%$ and 0.980 for $A_{\mathrm{sw}}$ in Figure 5, 11.9\% and 0.977 for $A_{\text {st }}$ in Figure 6, and $7.0 \%$ and 0.974 for $t_{\mathrm{s}}$ in Figure 7 , and the predicted values are presented in Figures 3(b) to 7(b).

\section{Discussion}

Studying (3)-(7) leads to the following notes:

For noncomposite, nonhybrid steel section $\left(F_{\mathrm{yf}}=F_{y w}=F_{y}, \alpha=1, \eta=1\right)$,

$$
\begin{aligned}
& H_{s}=7.0 \sqrt[3]{\frac{M}{F_{y}^{2}}}, \\
& A_{s c}=A_{s t}=A_{s w}=0.22 \sqrt{\left(\frac{M}{F_{y}}\right)^{2}} .
\end{aligned}
$$

This means that the optimum design for nonhybrid steel section neglecting the lateral torsional bulking is achieved when $A_{\mathrm{sc}}=A_{\mathrm{st}}=A_{\mathrm{sw}}$.

For fully shored composite, nonhybrid steel section $\left(F_{\mathrm{yf}}=F_{\mathrm{yw}}=F_{y}, \alpha=0, \eta=1\right)$,

$H_{s}=6.4 \sqrt[3]{\frac{\mathrm{M}}{F_{y}^{2}}}$

$A_{\mathrm{st}}=A_{\mathrm{ws}}=0.17 \sqrt[-3]{\left(\frac{M}{F_{y}}\right)^{2}}, A_{\mathrm{sc}}=0.057 \sqrt[3]{\left(\frac{M}{F_{y}}\right)^{2}} \approx 33 \% A_{\mathrm{st}}$.

This means that the optimum design for fully shored composite, nonhybrid steel section is achieved when $A_{\mathrm{st}}=A_{\mathrm{sw}}=3 A_{\mathrm{sc}}$. Moreover, it could be noted that the optimum depth and total steel weight are about $90 \%$ and $62 \%$ of those of the equivalent pure steel section, respectively. 


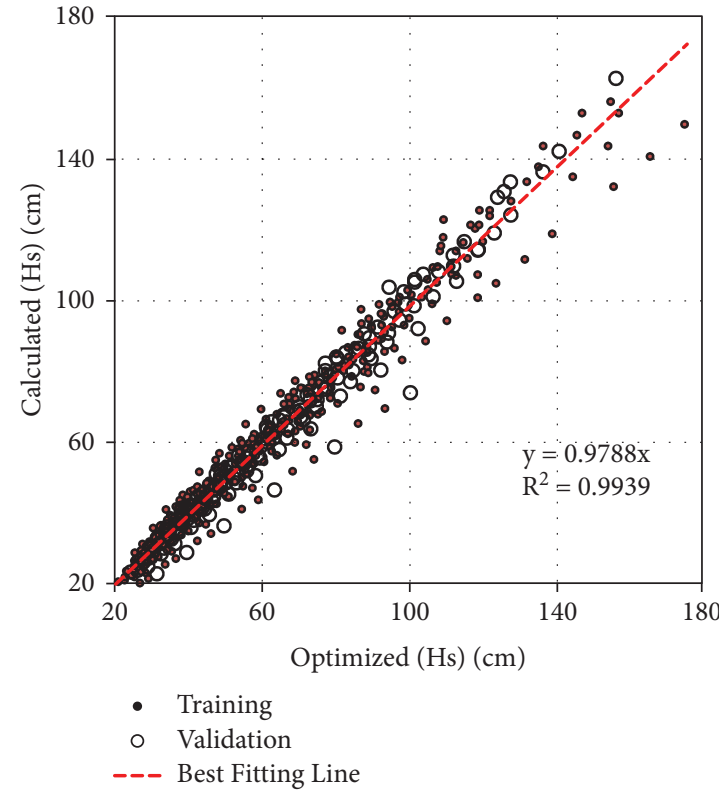

(a)

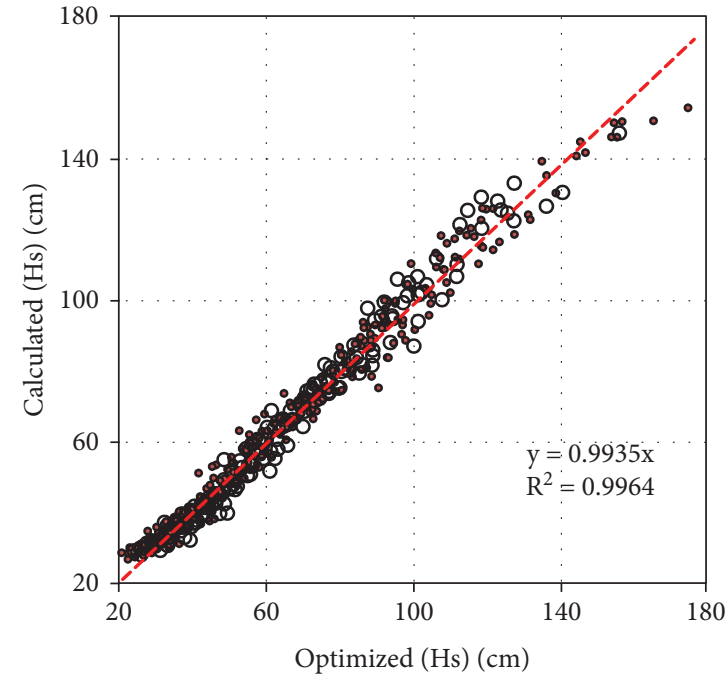

- Training

- Validation

--- Best Fitting Line

Figure 3: Relation between predicted and calculated $H_{s}$ values using the developed models. (a) NLR. (b) ANN.

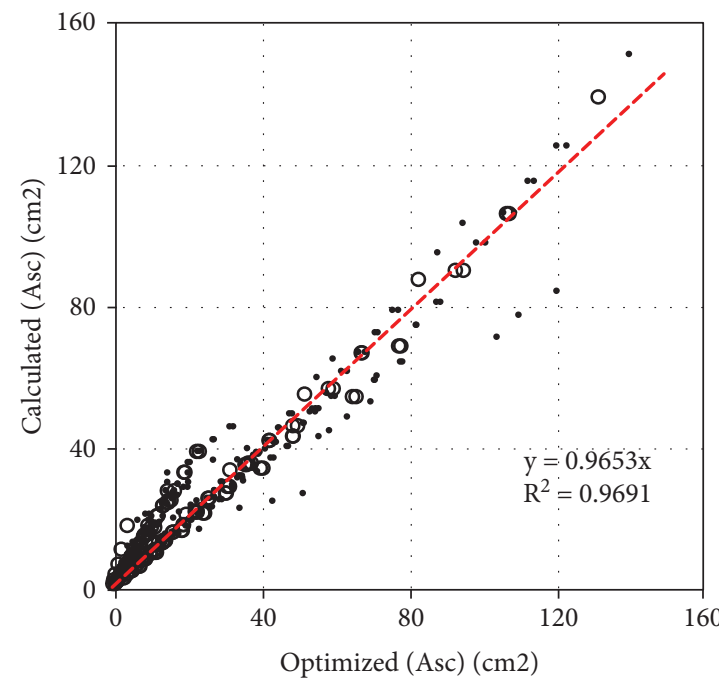

- Training

- Validation

--- Best Fitting Line

(a)

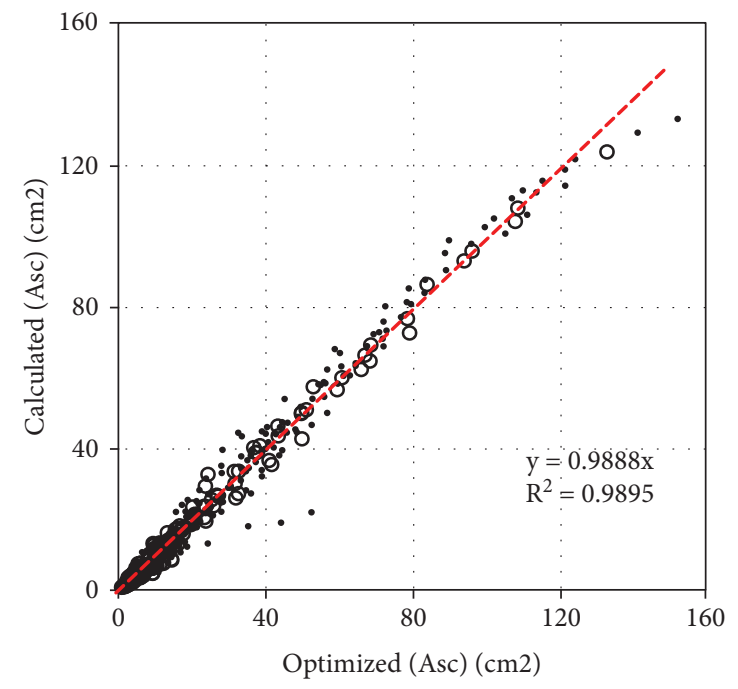

- Training

- Validation

--- Best Fitting Line

(b)

FIgURE 4: Relation between predicted and calculated $A_{\text {sc }}$ values using the developed models. (a) NLR. (b) ANN. 


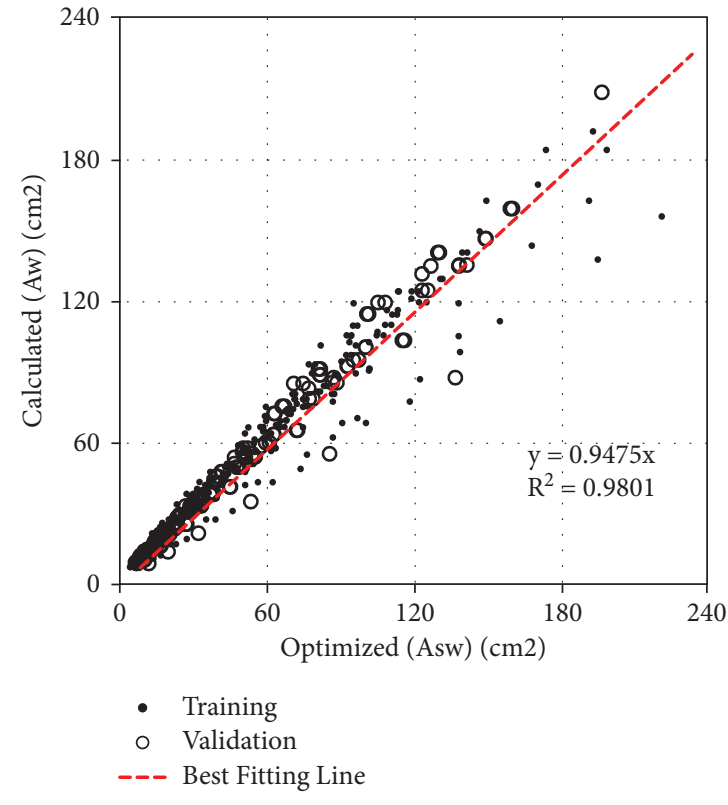

(a)

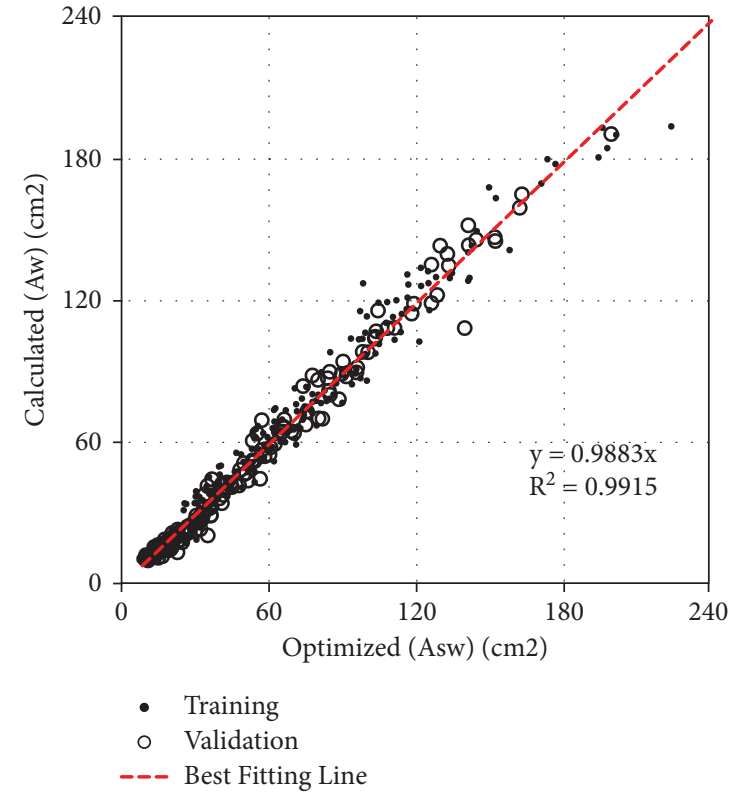

(b)

FIgURE 5: Relation between predicted and calculated $A_{\text {sw }}$ values using the developed models. (a) NLR. (b) ANN.

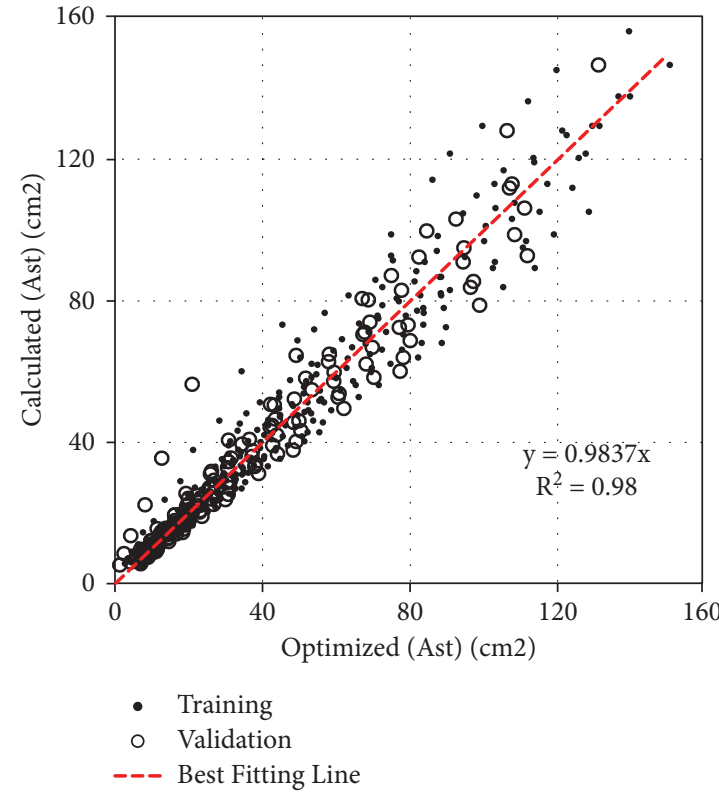

(a)

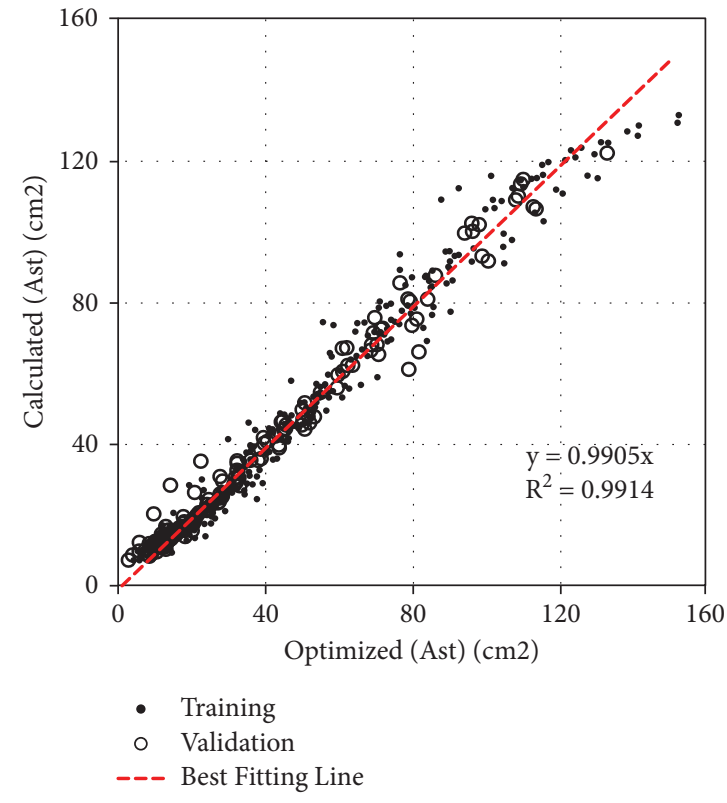

(b)

Figure 6: Relation between predicted and calculated $A_{\text {st }}$ values using the developed models. (a) NLR. (b) ANN. 


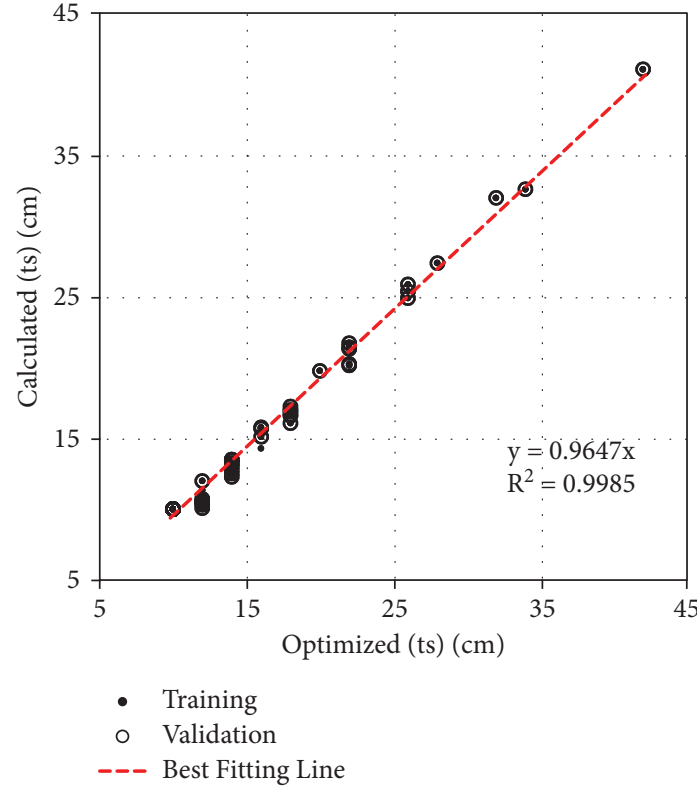

(a)

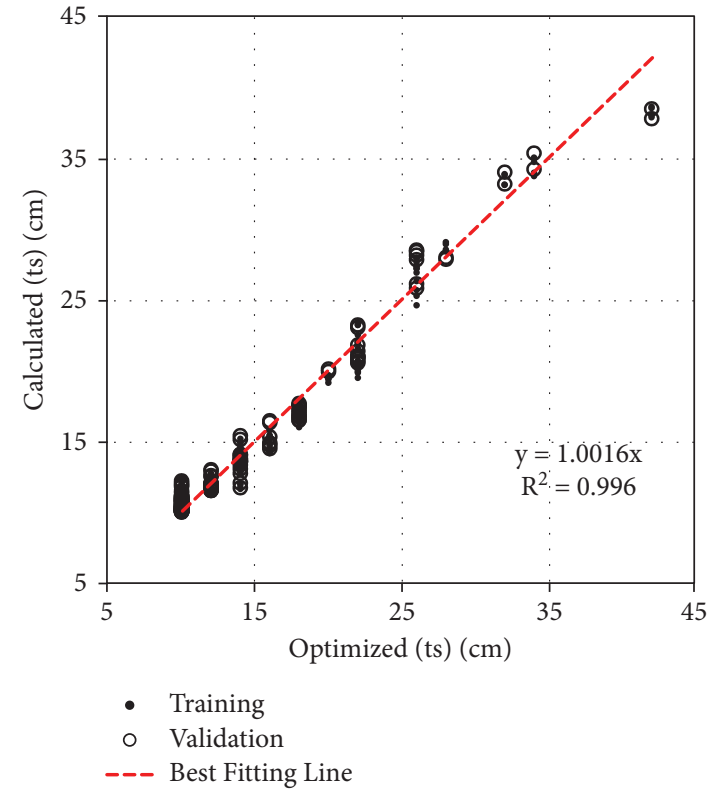

(b)

FIGURE 7: Relation between predicted and calculated $t_{s}$ values using the developed models. (a) NLR. (b) ANN.

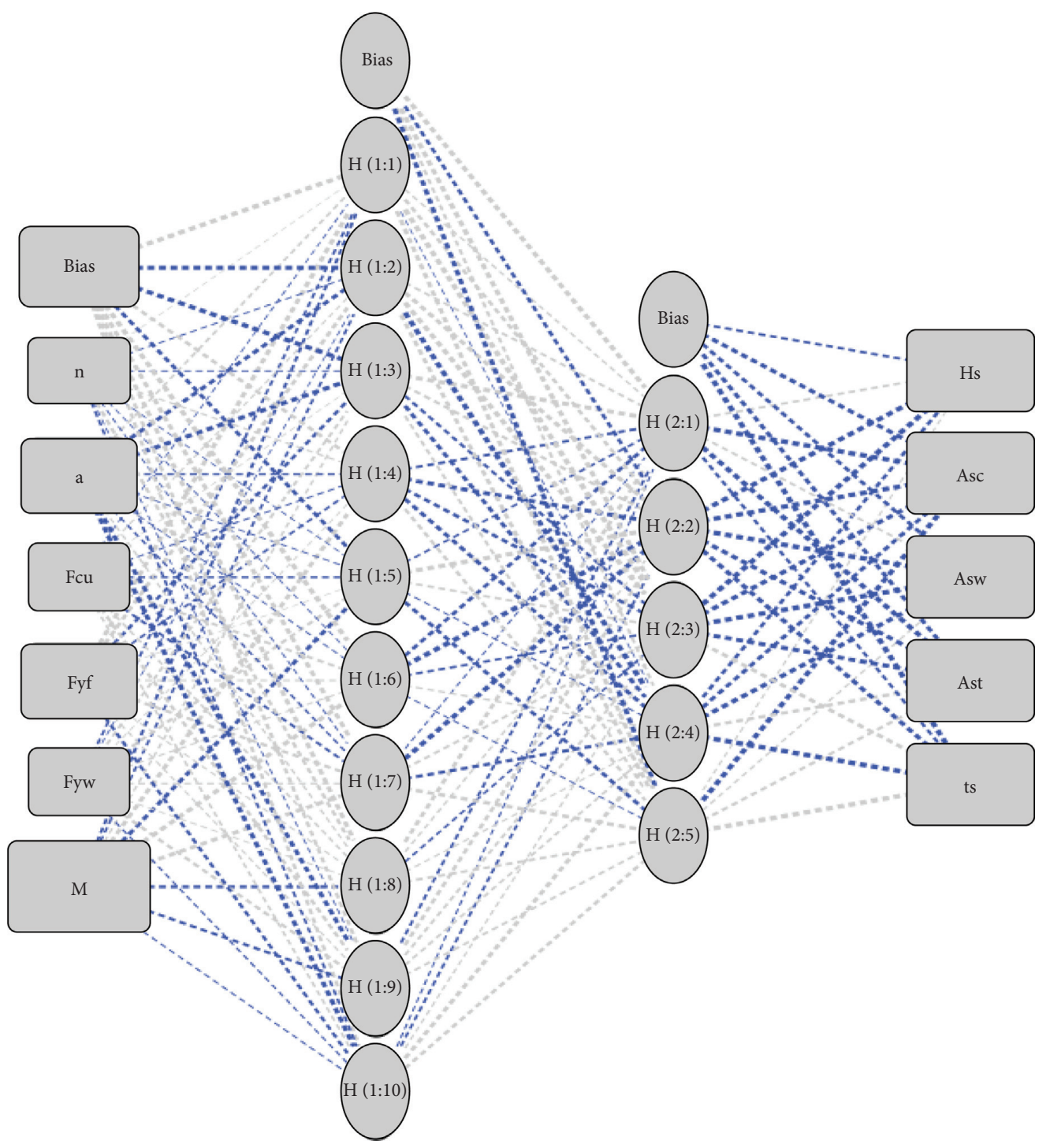

FIgURE 8: Layout for the developed ANN and its connection weights. 


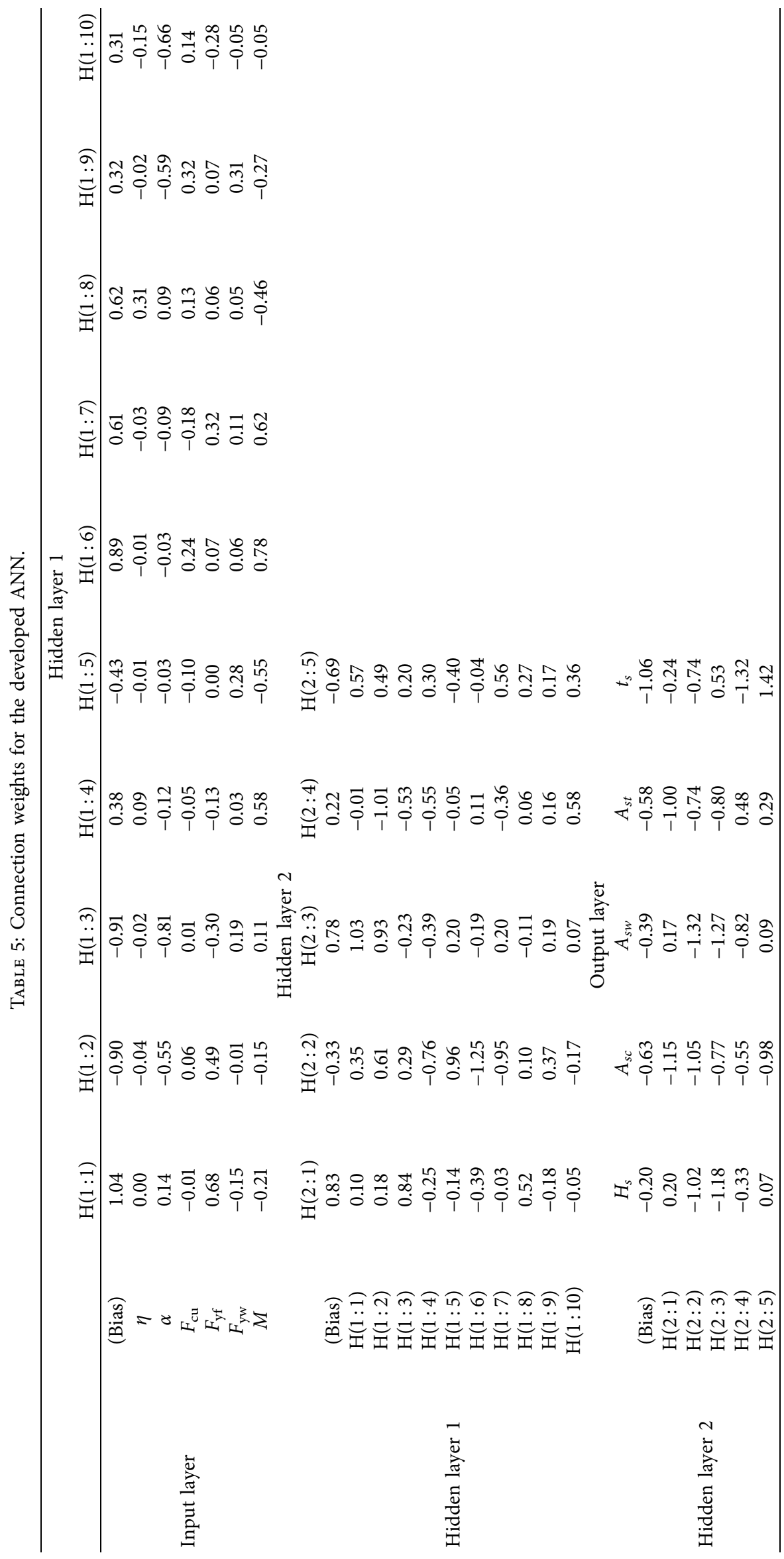


For unshored composite, nonhybrid steel section $\left(F_{\mathrm{yf}}=F_{\mathrm{yw}}=F_{y}, \alpha=0.33, \eta=1\right)$,

$$
\begin{aligned}
& H_{s}=6.6 \sqrt[3]{\frac{M}{F_{y}^{2}}} \\
& A_{\mathrm{st}}=A_{\mathrm{sw}}=0.19 \sqrt[3]{\left(\frac{M}{F_{y}}\right)^{2}}, \\
& A_{\mathrm{sc}}=0.09 \sqrt[3]{\left(\frac{M}{F_{y}}\right)^{2}} \approx 50 \% A_{s t} .
\end{aligned}
$$

For unshored composite, nonhybrid steel section, where the initial load is about $33 \%$ of the total load (which is the common case in residential and office buildings), the optimum design is achieved when $A_{\mathrm{st}}=A_{\mathrm{sw}}=2 A_{\mathrm{sc}}$. Furthermore, it could be noted that the optimum depth and total steel weight are about $95 \%$ and $73 \%$ of those of the equivalent pure steel section, respectively.

\section{Conclusions}

This research presents two predictive models to determine the optimum cross section dimensions of fully composite, unstiffened, built-up, hybrid steel girders. The research program was divided into two phases. The first is to generate a dataset of composite beams with optimized cross sections based on their steel grades, construction sequences, and material prices besides the bending moments. This phase was carried out using GRG technique and produced a dataset of 504 records. In the second phase, the generated dataset is divided into a training set used to develop the predictive models and a validation set used to test the validity of these models. Two techniques were used to develop the models, one mathematical technique (NLR) and one soft computing technique (ANN). The results of the present research revealed the following:

(a) The average prediction accuracy of NLR and ANN models is about $92.8 \%$ and $93.1 \%$ for section dimensions $\left(H_{s}, t_{s}\right)$ and $78.5 \%$ and $86.5 \%$ for section weights $\left(A_{\mathrm{sc}}, A_{\mathrm{sw}}, A_{\mathrm{st}}\right)$, respectively.

(b) Although, the ANN model is more accurate than NLR model, it is more complicated and cannot be manually used, which gives an advantage to NLR model which introduces a set of simple closed form equations.

(c) The summation of the absolute weights of each neuron in the input layer of the ANN models indicates the importance of each input parameter. Accordingly, bending moment $(M)$ is the most important parameter, and both $F_{\mathrm{yf}}$ and $a$ shared the second ranking. Finally, $F_{\mathrm{yw}}, \eta$, and $F_{\mathrm{cu}}$ are less important parameters. (d) The NLR developed equations are versatile and could be used to determine the optimum cross section dimensions for any design and construction parameter combinations as follows:

Shoring condition, presented by the ratio of initial to total bending moment $(\alpha)$

Even pure steel girders (noncomposite), where $\alpha=1$

Hybrid condition, presented by yield stresses of both flanges $\left(\mathrm{F}_{\mathrm{yf}}\right)$ and web $\left(\mathrm{F}_{\mathrm{yw}}\right)$

Economic condition, presented by the ratio of flange to web unit cost $(\eta)$

(e) Testing the NLR developed equations for wellknown common cases showed perfect matching as follows:

For noncomposite, nonhybrid steel section $\left(F_{\mathrm{yf}}=F_{\mathrm{yw}}=F_{y}, \quad \alpha=1, \quad \eta=1\right)$, the optimum steel section cost occurs when each flange has the same area as web

For fully shored composite, nonhybrid steel section $\left(F_{\mathrm{yf}}=F_{\mathrm{yw}}=F_{y}, \quad \alpha=0, \quad \eta=1\right)$, the optimum steel section cost occurs when both tension flange and web areas equal about $45 \%$ of the total steel section area, and the area of compression flange area is about one-third of the area of tension flange For unshored composite, nonhybrid steel section $\left(F_{\mathrm{yf}}=F_{\mathrm{yw}}=F_{y}, \alpha=0.33, \eta=1\right)$, the optimum steel section cost occurs when both tension flange and web areas equal about $40 \%$ of the total steel section area, and the area of compression flange area is about half the area of tension flange

(f) Like any other regression technique, the generated formulas are valid within the considered range of parameter values; beyond this range, the prediction accuracy should be verified.

\section{Data Availability}

The data supporting the outcome of this research work are included within the manuscript.

\section{Conflicts of Interest}

The authors declare no conflicts of interest regarding the publication of this paper.

\section{References}

[1] B. S. Dhillon and C.-H. Kuo, "Optimum design of composite hybrid plate girders," Journal of Structural Engineering, vol. 117, no. 7, 1991.

[2] S. Hendawi and D. M. Frangopol, "Design of composite hybrid plate girder bridges based on reliability and optimization," Structural Safety, vol. 15, no. 1-2, pp. 149-165, 1994.

[3] H. Adeli and H. Kim, "Cost optimization of composite floors using neural dynamics model," Communications in Numerical Methods in Engineering, vol. 17, no. 11, pp. 771-787, 2001. 
[4] H. Kim and H. Adeli, "Discrete cost optimization of composite floors using a floating-point genetic algorithm," Engineering Optimization, vol. 33, no. 4, pp. 485-501, 2001.

[5] S. Kravanja and S. Silih, "Optimization based comparison between composite I-beams and composite trusses," Journal of Constructional Steel Research, vol. 59, pp. 609-625, 2002.

[6] C. M. Foley and W. K. Lucas, "Optimal selection and design of composite steel floor systems considering vibration," Structures, vol. 28, 2004.

[7] M. Veljkovic and B. Johansson, "Design of hybrid steel girders," Journal of Constructional Steel Research, vol. 60, no. 3, pp. 535-547, 2004.

[8] U. Klanšek and S. Kravanja, "Cost estimation, optimization and competitiveness of different composite floor systems-Part 1: self-manufacturing cost estimation of composite and steel structures," Journal of Constructional Steel Research, vol. 62, no. 5, pp. 434-448, 2006.

[9] U. Klanšek and S. Kravanja, "Cost optimization of composite I beam floor system," American Journal of Applied Sciences, vol. 5, no. 1, pp. 7-17, 2007.

[10] S. Kravanja and U. Klanšek, "Cost optimization of composite floors," WIT Transactions on The Built Environment, vol. 97, 2019.

[11] A. B. Senouci and M. S. Al-Ansari, "Cost optimization of composite beams using genetic algorithms," Advances in Engineering Software, vol. 40, no. 11, pp. 1112-1118, 2009.

[12] A. Kaveh, M. Abadi, and S. M. Abadi, "Cost optimization of a composite floor system using an improved harmony search algorithm," Journal of Constructional Steel Research, vol. 66, no. 5, pp. 664-669, 2010.

[13] A. Kaveh and M. Ahangaran, "Discrete cost optimization of composite floor system using social harmony search model," Applied Soft Computing, vol. 12, no. 1, pp. 372-381, 2012.

[14] V. E. Roşca, A. Elena, and C. E. Teleman, "Practical optimization of composite steel and concrete girders," Buletinul Institutului Politehnic din Iasi. Electrotehnica, vol. 12, 2012.

[15] B. Blachowski, W. Gutkowski, and W. Gutkowski, "Minimum weight design of composite floors under human induced vibrations," Journal of Civil Engineering, Environment and Architecture, vol. 61, no. 61, pp. 5-14, 2014.

[16] R. Abspoel and F. Bijlaard, "Optimization of plate girders," Steel Construction, vol. 7, no. 2, pp. 116-125, 2014.

[17] A. J. Unander, "Optimization of composite floors: theory and practice," M. Sc. Thesis, University of Illinois, UrbanaChampaign, 2016.

[18] E. Hamid and T. Korouzhdeh, "Cost optimization and sensitivity analysis of composite beams," Civil Engineering Journal, vol. 2, no. 2February, 2016.

[19] H. Rong, G. Ding, Y. Yang, and L. Ye, "Structural design and optimization of long-span ultra-slim composite floor for super tall residence," in Proceedings of the 2016 Structures Congress (Structures16), Jeju Island, Korea, August 2016.

[20] P. Juhás, "Fatigue failure mechanisms of thin-walled hybrid plate girders," MATEC Web of Conferences, vol. 93, Article ID 01001, 2017.

[21] T. Korouzhdeh, H. Eskandari-Naddaf, and M. Gharouni-Nik, "An improved ant colony model for cost optimization of composite beams," Applied Artificial Intelligence, vol. 31, no. 1, pp. 44-63, 2017.

[22] A. R. Silva and T. A. Rodrigues, "Optimized dimensioning of steel-concrete composite beams," Revista IBRACON de Estruturas e Materiais, vol. 12, no. 6, pp. 1428-1453, 2019.

[23] N. M. Yossef and S. Taher, "Cost optimization of composite floor systems with castellated steel beams," Practice Periodical on Structural Design and Construction, vol. 24, no. 1, Article ID 04018035, 2019.

[24] T. Korouzhdeh and H. Eskandari-Naddaf, "Cost-safety optimization of steel-concrete composite beams using standardized formulation," Engineering Science and Technology, an International Journal, vol. 22, no. 2, pp. 523-532, 2019.

[25] Y.-B. Shao, Y.-M. Zhang, and M. F. Hassanein, "Strength and behaviour of laterally-unrestrained S690 high-strength steel hybrid girders with corrugated webs," Thin-Walled Structures, vol. 150, Article ID 106688, 2020.

[26] A. M. Ebid, "Optimum cross section and longitudinal profile for unstiffened fully composite steel beams," Future Engineering Journal, vol. 2, pp. 2314-7237, 2021.

[27] F. Saghira, S. Goharia, F. Mozafaric, N. Moslemid, C. Burvilla, and S. Lucasb, "Mechanical characterization of particulated FRP composite pipes: a comprehensive experimental study," Polymer Testing, vol. 93, 2021.

[28] A. A. Katsamakas, V. K. Papanikolaou, and G. E. Thermou, "A FEM-based model to study the behavior of SRG-strengthened R/C beams," Composite Structures, vol. 266, 2021.

[29] S. Goharia, S. Mouloodia, F. Mozafarib et al., "A new analytical solution for elastic flexure of thick multi-layered composite hybrid plates resting on Winkler elastic foundation in air and water," Ocean Engineering, vol. 23, 2021. 